INTERRELATIONSHIPS AMONG LEADERSHIP STYLE, ORGANIZATIONAL CLIMATE, AND TEAM EFFECTIVENESS AMONG SELECTED HIGH SCHOOL ADMINISTRATIVE TEAMS

BY

WILERED FRENKLIN STILL

A DISSERTATION PRESENTED TO THE GRADUATE CCUNICIL OF THE UNIVERSITY OF FLORIDA

IN PARTIAL EULFILLMENT OF THE REQUIREMENTS FOR THE DEGREE OF DOCTOR OF PHILOSOPLY

UNIVERSTTY $O E$ FLORIDA

1979 


\section{ACKNOWLEDGMENTS}

The writer wishes to express his gratitude to the members of the doctoral committee: Dr. Ralph B. Kimbrough, Chairman, Dr. Michael Y. Nunnery, and Dr. William D. Hedges. The educational and professional experiences of the writer were greatly enhanced by each member of the committee.

The writer also is greatly appreciative of his wife, Jackie, and all others who encouraged him while this study was being conducted. 
TABLE OF CONTENTS

Page

ACKNOWLEDGMENTS . . . . . . . . . . . . . . . . ii

IIST OF TABLES . . . . . . . . . . . . . . . . . V V

ABSTRACT ..................... . . vii

CHAPTER

I. INTRODUCTION . . . . . . . . . . . . . . I

The Problem.............. . 6

Assumptions . . . . . . . . . . . . . . . 10

Definition of Terms . . . . . . . . . . . 10

Hypotheses . . . . . . . . . . . . . 14

Procedures . . . . . . . . . . . . . . . . 15

Organization of the Study:. . . . . . . 22

II. REVIEW OF RELATED LITERATURE . . . . . . . 23

Overview of Leadership Thecry and Research 23

Fiedler's Contingency Model. . . . . . . . 30

Description of the High School Leadership

Situation . . . . . . . . . . . . . 49

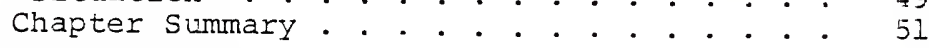

iI. PRESENTATION OF THE DATA . . . . . . . . 55

Initial Phase Data .......... . 56

Final Phase Data . . . . . . . . . . . . 64

Statistical Analysis of Data . . . . . . 66

Chapter Sumnary . . . . . . . . . . . 78

IV. DISCUSSION AND EXPLANATION OF FINDINGS . . 80

Relationship Between Leadership Style and

Team Effectiveness . . . . . . . . . . .

Relationship Between Organizational climate and Team Effectiveness........... Relationship Between Leadership Style and organizational Climate. . . . . . . . . . 97

Incerrelationships Among Leadership Style, Organizational Climate, and Team Effec-

tiveness . . . . . . . . . . . . . . . 90

Chapter Summary . . . . . . . . . . . 100 
CHAPTER

V. SUMMARY, CONCLUSIONS, AND IMPLICATIONS . . . 102 Summary . . . . . . . . . . . . . 102

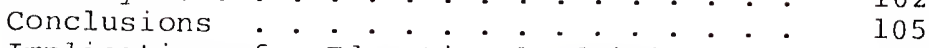
Implications for Educationai Administra-

APPENDIX

A. LETter to principals . . . . . . . . . . . 114

B. HIGH SCHOOL CHARACTERISTICS INDEX ADMINISTRATION INFORMATION . . . . . . . . . . 115

REFERENCES • . . . . . . . . . . . . . . . . . . . 117

BIOGRAPHICAL SKETCH . . . . . . . . . . . . . . 123 
LIST OF TABLES

Table

Page

1. Predicted Correlations Between Leader LPC Scores and Group Effectiveness According to Fiedler's Contingency Model

2. Least Preferred Coworker Scores of the Principals

3. Administrative Team Membership and Mean GA Scores

4. Rank Order of Schools According to Mean GA Scores

5. Mean GA Scores Indicated by Administrative Teams in Final Sample

6. Principal GA Scores and Mean Group GA Scores

7. Developmental Press HSCI Data

8. Principals' LPC Scores and Team HSCI Scores

9. Rank Order of Team HSCI Scores Indicated by High LPC and Low LPC schools

10. Developmental Press HSCI Data Indicated by High GA and Low GA Schools

11. Rank Order of Team HSCI Scores Indicated by High GA and Low GA Schools

12. LPC Scores and Mean GA Scores Listed by School

13. Rank order of LPC Scores and Mean GA Scores Indicated by the Initially selected Schools

14. Principals' LPC Scores and Team ISCI Scores within High GA Schools

15. Rank order of LPC Scores and HSCI Scores Within High GA Schools 
Table

Page

16. Principals' LPC Scores and Team HSCI Scores Within Low GA Schools

17. Rank Order of IPC Scores and HSCI Scores Within Low GA Schools

18. Categorization of the Leadership Situation According to octants 
Abstract of Dissertation Presented to the Graduate council

of the University of Florida in Partial Fulfillment of

the Requirements for the Degree of Doctor of Philosophy

\author{
INTERRELATIONSHIPS AMONG LEADERSHIP STYLE, \\ ORGANIZATIONAL CLIMATE, AND TEAM EFFECTIVENESS \\ AMONG SELECTED HIGH SCHOOL ADMINISTRATIVE TEAMS
}

By

\title{
Wilfred Franklin still
}

\section{August 1979}

Chairman: Dr. Ralph B. Kimbrough

Major Department: Educational Administration

The problem of this study focused upon the interrelationships among leadership style, organizational climate, and group effectiveness among selected high school administrative teams. A secondary emphasis of this research was to examine the relevancy of the contingency model of leadership effectiveness developed by Fiedler for selected high schools. Answers to the following questions were sought during the course of this investigation:

1. Is there a relationship between the leadership style of principals and the effectiveness of high school administrative teams?

2. Is there a relationship between the organizational climate of the administrative tearn and the effectiveness of the administrative team? 
3. Is there a relationship between the leadership style of principals and the organizational climate of the administrative teams?

4. Is there a relationship between the ieadership style of principals and the effectiveness of high school administrative teams having a most cooperative group climate?

5. Is there a relationship between the leadership style of principals and the effectiveness of high school acministrative teams having a least cooperative group climate?

The principals and administrative teams of $20 \mathrm{high}$ schools constituted the initial sample of the study. The Least Preferred Coworker (LPC) scale, developed by Fiedler, was used to identify the principal's leadership styie. The organizational climate of the administrative team was measured with the Group Atmosphere (GA) scale, developed by Fiedier, The six administrative teams indicating the most cooperative organizational climate and the six teams indicating the least cooperative organizational climate comprised the population of 12 administrative unics selected for the Einal sample of the study. The effectiveness of the high school administrative teams comprising this Einal sample was measured by utilizing the High school Characteristics Index (HSCI) developec by Stern. 
No statistically significant relationships were found during the process of answering the five research questions associated with this study $(\underline{p}<.05)$.

The writer concluded that no significant interrelationships existed among leadership style, organizational climate, and team effectiveness among high school administrative teams selected for this study. However, the correlations found during the analysis of data associated with questions 4 and 5 were in the negative and positive direction, respectively. These correlations were both in the direction predicted by Fiedler. Statements made by Fiedler and other writers in the literature suggested that these findings support the contingency model of leadership effectiveness. 
CHAPTER I

INTRODUCTION

Effective organizational performance is a significant goal of formal organizations. Many factors contribute to the effective performance of organizations. One of the most significant factors affecting organizational performance is leadership. Hellriegel and Slocum (1976) emphasized the significance of leadership in attaining effective performance of people in organizations in the following statement:

While many different sets of factors are potentially important, it is clear that leaders are in a position to exercise great influence over these factors. The effectiveness of the manager is probably the single most important factor in affecting the performance of subordinates. (p. 291)

Ivancevich, Szilagyi, and Wallace (1977) placed much significance on the leadership element in organizations when they stated,

Leadership has been considered one of the most important elements affecting organizational performance. For the manager, leadership is the focus of activity through which the goals and objectives of the organization are accomplished. (p. 269)

As in other formal organizations, the leadership element in educational institutions is a factor 
contributing to organizational performance. Schultz

focused attention upon leadership responsibilities of

school administrators in a 1977 publication:

School administrators are key elements in the question of quality education. While teachers are certainly the pivotal figures in the educational process, their efforts are sometimes limited, subverted, or nulified by poor administrators. Good administrators tend to encourage, enhance, and help release teachers' potential. In any organization, the person at the top sets the tone. . . Educational upgrading requires the improvement of schocl administration. (p. 1)

While placing importance on teachers' roles in providing educational services, Campbell, Bridges, and Nystrand (1977) also focused on the principalship in this comment:

We do not wish to minimize the roles played by classroom teachers as the public schools attempt to meet their obligations. Teaching and learning go on only through the teachers. At the same time, teachers and researchers alike have repeatedly indicated that a good part of what any school does is dependent upon the administrative leadership given to that school. The principal, for instance, has a key role in setting the tone, establishing the conditons, and proviaing the stimulation for the kind of living and learning in his school. (p. 381)

The principal of a high school in many communities is the leader of a large organization. A survey of the 1978-79 high school enrollments provides support for the notion that high schools with enrollments in excess of 1,500 students are not rare curriculum Information Center, 1978). While the principal is responsible for 
accomplishing the numerous administrative tasks associated with managing a large high school, this one person does not complete these tasks without assistance. The principalship of a large high school consists of an administrative team, rather than a single individual. The high school principal of the 1970 s is assisted by an assembly of administrative assistants, deans, business managers, secretaries, and clerical assistants. This group of people together engages in the necessary administrative processes for accomplishing the tasks of the principalship. While existence of the administrative team does relieve the principal of much of the direct responsibility for the operation of the school, it is imperative that the principal provide effective leadership for this team to be productive (Gorton, 1976, p. 86). Emphasizing the importance of this leadership function, Holland (1968) stated that "if the principal does not assume this function, he will cease to be the navigator of the educational ship and beccme only its figurehead" (p. 65).

High school principals have been observed employing a wide range of styles while engaged in the process of leadership (Evenson, 1959). The leadership style employed by a principal will be a reflection of the leader's personality (Fiedler, 1969). Fiedier (1967) described the leadership style of a leader along a task-orientedinterpersonal relationship-oriented continuum (pp. 36-60). 
This description is based upon the underlying needstructure of the individual. This need-structure motivates a leader's behavior in various leadership situations and is responsible for the consistency of leadership style over different situations.

The stability of the leadership style phenomenon was shown when Fiedler (1969) stated:

Changing a man's leadership style means trying to change his personality. . . A leader's style is not likely to change because of a few lectures or even a few weeks of intensive training. (p. 43)

Individuals interacting as do the high school administrative team comprise the interpersonal aspect of the organization (Fiedler \& Chemers, 1974, p. 57). This interpersonal aspect of the organization is also referred to in the literature as organizational climate or atmosphere. Burns and stalker (1961) defined organizational climate in terms of a mechanistic-organic continuum. Descriptions such as friendly-unfriendly, cooperative-uncooperative, and tense-relaxed are among those used by Fiedler (1967) to describe the personality of a group (p. 32).

A major goal of educational institutions is to provide a situation where effective learning is likely to occur (Garland \& O'Reilly, 1976). Effective performance of the high school administrative team is essential for providing a school environment conducive to learning. Bishop (1971) shared his views on the administrative 
staff's responsibility for providing an appropriate learning environment:

While it is recognized that teachers share responsibility with the administration of any school for the establishment of a climate which is open and conducive to healthy student interactions and productive interpersonal relations, the author is equally convinced that the creation of any type of school environment, be it open or closed, must be placed first upon the principal and his immediate administrative staff. (p. 220)

The quality of the learning climate provided for students, therefore, is a legitimate indication of administrative team effectiveness.

The leadership style of the principal is constantly interacting with the climate of the school administrative team. Educational administrators are interested in being able to enhance group performance. The interaction of leadership style with group climate can be related to group performance. Fiedler and Chemers (1974) commented on this matter:

Whether or not certain organizational climates produce, or are associated with, more effective performance, it seems likely that organizational climate will interact with the leader's task- or relationship-motivation in affecting organizational performance. (p. llo)

Fiedler (1967) developed a model of leadership effectiveness. According to this model, the performance of a group is contingent upon both the leadership style of the leader and the degree to which the situation favors the leader's style. Fiedler's Contingency Model supports the 
postulate that it is important for district-level administrators to consider both the climate of the work group and leadership style when selecting principals for schools (p. 247).

A study of the application and extension of Fiedler's Contingency Model to the leadership situation present within selected high school administrative teams seemed appropriate in view of the predictive and heuristic functions this theory potentially can provide for the field of educational administration.

\section{The problem}

Statement of the Problem

This study was focused upon the interrelationships among leadership style, organizational climate, and team effectiveness among selected high school administrative teams. During the course of this investigation answers to the following questions were sought:

1. Is there a relationship between the leadership style of principals and the effectiveness of high school administrative teams?

2. Is there a relationship between the organizational climate of the administrative team and the effectiveness of the administrative team?

3. Is there a relationship between the leadership style of principals and the organizational climate of the administrative teams? 
4. Is there a relationship between the leadership style of principals and the effectiveness of high school administrative teams having a most cooperative group climate?

5. Is there a relationship between the leadership style of principals and the effectiveness of high school administrative teams having a least cooperative group climate?

\section{Delimitations}

The scope of this investigation was restricted to the relationships among three variables: (a) the leadership style of the high school principal, (b) the organizational climate of the administrative team, and (c) the effectiveness of the administrative team. Twenty selected high schools in four school districts of Florida were included in the analysis.

The scope of this investigation was also restricted by the latitude of the instruments selected to measure the variables. The Least Preferred Coworker (LPC) scale, developed by Fiedler (1967), was used to measure the leadership style of principals. The organizational climate of administrative teams was measured with the Group Atmosphere (GA) scale designed by Fiedler (1967). The High School Characteristics Index (HSCI), developed by Stern (1970), was used to measure the effectiveness of the administrative teams. 
Additional restrictions to the scope of this investigation were the number of administrative teams, administration team members, and students selected to complete the research instruments used in this study. A total of 20 high school principals completed the LPC scale. The number of administrative team members in each school ranged from 8 to 16 . A total of 221 administrative team members provided usable responses to the GA scale. The number of students selected from each school to participate in this study ranged from 61 to 90 . A total of 739 students from 12 schools provided usable responses to the HSCI.

\section{Limitations}

Several limitations should be considered regarding this study.

Since the study was limited to 20 accessible schools in a single state, one may not generalize the results to the population of high schools at large. That is, to the extent that the principals, administrative teams, and high schools selected are not representative of the population of these subjects at large, results cannot be generalized beyond the sample investigated.

since this study was an ex post facto investigation, only a relationship among the variables can be established. causality could not be determined through this study. 
Events occurring during the duration of the investigation may have affected the validity and reliability of the measurements of the variables associated with the research problem.

\section{Justification for the study}

This study added information to the growing body of knowledge about leadership, which is considered one of the most significant factors affecting organizational performance (Hellriegel \& Slocum, 1976; Ivancevich et al., 1977; Schultz, 1977).

Information relevant to the usefulness of Fiedler's Contingency Model when applied to the high school setting was provided by this study.

knowledge useful for effectively utilizing the talents of leaders in the most appropriate situations was gained from this study of the applicability of Fiedler's theories to the high school principalship (1967, p. 247).

Further justification for this study is derived from the opinion of Fiedler and Chemers concerning the significance of a study conducted by Csoka (1972) in which the interrelationships among leadership style, group climate, and group performance were studied. Fiedler and Chemers (1974) commented as follows:

This study is important for two reasons. First of all, it provides a bridge between the Contingency Model and a large area of organizational theory which has been relatively 
unconcerned with an interactional approach to leadership. Second, it shows how the larger organization affects the operation of its subunits. (p. 111)

The principal of a high school is responsible for providing the services which the administrative team disseminates throughout the organization. The principalship position has great influence upon the degree to which the goals of high schools are achieved (Anderson \& Van Dyke, 1963; Bishop, 1971; Campbell et al., 1977; Gorton, 1976). A study focusing upon the leadership function of the principalship seemed appropriate in light of this position's significance to the effectiveness of the organization.

\section{Assumptions}

An assumption was made that the leadership situation, as defined in Fiedler's Contingency Model (1967), is essentially the same in high schools having an enrollment in excess of 1,500 students. An additional assumption critical to this study was that the measurement techniques utilized would demonstrate sufficient reliability and validity for the data generated to be appropriately paralleled with the contingency model.

\section{Definition of Terms}

Administrative team. This is defined as the group of persons whose primary occupational responsibility is to 
accomplish the administrative tasks associated with the operation of a high school. This group includes the principal, assistant principals, administrative assistants, deans, business managers, secretaries, and clerical assistants of the high school.

Effectiveness of the administrative teams. Conceptually, this term is defined as the degree of success achieved by the administrative team in providing students with a self-actualizing environment (Stern, 1970, pp. 288292). Operationally, this term refers to the mean "developmental press" score derived from the responses of a sample of students in each school participating in this study on Stern's High School Characteristics Index (HSCI). Final sample. This term refers to the 12 administrative teams that were selected after the 20 administrative teams sampled initially had completed the Group Atmosphere (GA) scale. The mean GA scores for the administrative teams were ranked from the highest to the lowest. The administrative teams with the six highest GA scores and the six lowest GA scores were selected for the final sample.

Group Atmosphere (GA) scale. This term refers to the instrument selected to measure the organizational climate of the administrative teams.

IIigh Least Preferred Coworker scores. Operationally, this term refers to scores indicated on the Least Preferred Coworker scale that are greater than or equal to 70 . 
High school. A school is defined as a high school if it includes the grade levels 9, 10, 11, and 12 or 10, 11, and 12 .

Initial sample. This term refers to the 20 administrative teams that were selected at the beginning of this study

Leadership. This term is defined as a relationship between people in which influence and power are unevenly distributed on a legitimate basis. The leader-follower interaction involves some kind of psychological or economic exchange (Fiedler \& Chemers, 1974, p. 4).

Leadership situation. This term refers to environmental factors within the organization that tend to affect the performance of the principal. The nature of the group task, the organizational climate, and the leader's position power are significant environmental factors that comprise the leadership situation (Fiedler \& Chemers, 1974, pp. 5672).

Leadership style. Conceptually, this term is defined as a relatively enduring set of behaviors which is characteristic of the leader regardless of the situation (Fiedler \& Chemers, 1974, p. 40). Operationally, this term is defined as the score resulting from the leader's responses on Fiedler's Least Preferred Coworker (LPC) scale. 
Least cooperative group climate (10N GA). Operationally, this is defined as the organizational climate of an administrative team in which the team members' responses on Fiedler's Group Atmosphere (GA) scale result in a mean team score ranked 15 or lower out of 20 teams studied. Least Preferred Coworker (I.PC) scale. This term refers to the instrument selected to measure the leadership style of principals.

Low Least Preferred Coworker scores. Operationally, this term refers to scores indicated on the Least Preferred coworker scale that are less than 70 .

Most cooperative group climate (high GA). Operationally, this is cefined as the climate of an administrative team in which the team members' responses on Fiedler's Group Atmosphere (GA) scale result in a mean team score ranked six or higher out of 20 teams studied.

Organizational climate. Conceptually, this term is defined in terms of a cooperative-uncooperative continuum. operationally, the term is defined as the mean score resulting from the responses made by äministrative team members on Fiedler's Group Atmosphere scale.

Relationship-motivated leader (high LPC). Operationaliy, this term refers to a leader who scores greater than or equal to 70 on Fiedler's Least Preferred Coworker scale. Task-motivated leader (low LPC). Operationally, this term refers to a leader who scores less than 70 on Fiedler's Least Preferred Coworker scale. 


\section{Hypotheses}

During the course of this study the following five null hypotheses were tested. The level of significance for rejecting the null hypotheses was .05. These hypotheses are numbered according to the respective research questions to which they relate:

1. The High School Characteristics Index scores in final sample high schools led by principals having high Least Preferred Coworker scores do not differ from the High School Characteristics Index scores associated with principals indicating low Least Preferred Coworker scores.

2. The High School Characteristic Index scores associated with final sample administrative teams indicating high Group Atmosphere scores do not differ from the High School Characteristics Index scores associated with final sample administrative teams indicating low Group Atmosphere scores.

3. There is no correlation between the Least Preferred Coworker score of principals and the mean Group Atmosphere score among the initial sample administrative teams.

4. There is no correlation between the Least Preferred coworker score of principals and the mean High School Characteristics Index score among the final sample schools having administrative teams that indicated high Group Atmosphere scores. 
5. There is no correlation between the Least Preferred Coworker score of principals and the mean High School Characteristics Index score among the final sample schools having administrative teams that indicated low Group Atmosphere scores.

\section{$\underline{\text { Procedures }}$}

Overview of Research Design

This study was conducted to determine the relationship among the leadership style of the principal, the organizational climate of the administrative team, and the effectiveness of the administrative team in providing an appropriate learning environment for students. The principals and administrative teams of 20 schools were initially selected for the study. The leadership style of the principal and the organizational climate of the administrative team was measured by administering two instruments to the appropriate research subjects. The six administrative teams indicating the most cooperative organizational climate and the six teams indicating the least cooperative organizational climate comprised the 12 administrative units selected for the final sample of the study. The dependent variable, the team's effectiveness in providing an environment conducive to learning, was measured by assessing the student's perception of the quality of the learning environment provided. 


\section{Instrumentation}

Measurement of leadership style. The Least Preferred Coworker (LPC) scale, developed by Fiedler (1967), was used to identify the leader's style. Selection of this instrument was stimulated by its close association with the theoretical model upon which this study is based. This instrument consists of 16 eight-point bipolar scale items. The LPC score is the sum of the 16 item scores.

Internal consistency estimates for the LPC scale range from .85 to .95 . A test-retest reliability coefficient of .68 for the LPC score was reported by Fiedler (1967, p. 48). Using a six-weeks gap between evaluations, Garland and O'Reilly (1976) found the test-retest coefficient for the LPC scale to be .64 .

Measurement of organizational climate. The organizational climate of the administrative team was measured with the Group Atmosphere (GA) scale designed by Fiedler (1967). This instrument consists of 10 eight-point bipolar scale items. The GA score is the sum of the 10 item scores. A split-half reliability coefficient of .90 was reported for this instrument. In addition to the data concerning the split-half reliability, Fiedler indicated that the GA scale yielded consistent scores in three different task situations. Intercorrelations of $.76, .73$, and .83 were reported for the three sessions. 
Measurement of administrative team effectiveness. The effectiveness of the high school administrative team was measured by utilizing the High School Characteristics Index (HSCI), developed by Stern (1970), for completion by students. This instrument was developed by stern to measure the extent to which high schools provide experiences that enhance the development of human capacities. The HSCI has been demonstrated to measure effectively the quality of the learning environment afforded to students (Bishop, 1971; Garland \& O'Rei11y, 1976; Stern, 1970). The HSCI consists of 300 short true-false items that can be related to five first-order factors that are encompassed by a single second-order factor. This secondorder factor describing environmental variables that facilitate human growth was labeled "developmental press" by stern. Garland and O'Reilly have summarized the HSCI first-order factors that comprise the second-order factor, developmental press, as follows:

1. Intellectual climate. This factor reflects the qualities of a staff and plant specifically devoted to scholarly activities in the humanities, arts and social sciences. . .

2. Expressiveness. I'his factor suggests a non-conforming enviroment which encourages open emotional expression, high activity, aesthetic experiences, and expressions of dependence on others for assistance.

3. Group Life. Schools high on this factor are characterized by fun-loving, friendly, actively outgoing environments 
which provide for mutually supportive group activities of a warm, friendly nature.

4. Personal Dignity. This scale reflects a concern for the maintenance of a high level of self-determination and personal responsibility among students while providing for expressions of dependency and defensiveness. . . .

5. Achievement Standaras. This environment is characterized by high standards of achievement, an emphasis on striving for success through personal effort and on planned, organized, purposeful activities. . . (p. 16)

The Kuder-Richardson reliability coefficients for the first-order HSCI factors have been reported to range from .74 to .97 (Stern, 1970, pp. 254-255).

An examination of the relationship between the firstorder HSCI factors and the Blishen Occupational Class Scale resulted in Pearson correlations ranging from .01 to.06 (Gariand a O'Reilly, 1976). Garland and O'Reiliy argued that these correlations indlcate that the values, attitudes, and motivations reflected in a measure of sociseconomic status of students have no apparent inEluence on responses to the HSCI. Bishop (1971) studied the relationship between intellectual ability and HSCI scores. In reference to this study Bishop concluded that students, regardless of their intellectual ability, seem to share similar attitudes and perceprions concerning the characteristics of the learning environment (p. 210). 
Selection of the sample

Selection of the initial sample of schools. The administrative teams of 20 high schools in four school districts in Florida were the participants in this study. The smallest administrative team was comprised of eight members. The largest administrative team selected for this study had 16 members. The mean number of team members was 11.250. The selected county school districts were Brevard, Niarion, orange, and Volusia. The selected high schools all had a pupil enrollment of 1,500 or more. The principal of any selected school had occupied the position of principal in the sampled school during the school year prior to the time of this study. The 20 selected schools represented all of the schools within the selected districts that meet both the pupil enrollment and the continuity of principalship criteria.

Final sample selection. After the 20 previously selected administrative teams had completed the GA scale, a preliminary analysis of data available from the GA scale was conducted. The mean GA scores for the administrative teams were ranked from the highest to the lowest. The administrative teams with the six highest G $\mathrm{scores}$ and the six lowest $\mathrm{G} A$ scores were selected for the final sample.

Students from the schools associated with this final sample were selected to complete the HSCI. Students 
selected to complete the HSCI were all enrolled in the twelfth grade of the participating schools. This procedure of cluster sampling only twelfth grade students was recommended by Garland and O'Reilly (1976) and justified by data gathered by Bishop (1971) in conducting a study of this nature. A random selection was made of three sections in each school of a required twelfth grade course in which students were randomly assigned. The students enrolled in the selected sections completed the HSCI. The number of students selected from each school by this cluster sampling technique ranged from 61 to 90 . The mean number of students selected from a school was 69.583 .

\section{Cullection of the Data}

Data in the form of responses to the LPC and GA scales were collected by the researcher. The LPC scale was administered to the principals of the 20 administrative teams selected for the initial sample. The GA instrument was administered to all members of each administrative tearn sampled, including the principal. Arrangements for the administration of these scales was made by mail, telephone, and personal interview with the principals sampled. Both the LPC and GA scales are simple instruments that were completed by the respondents in a period of less than five minutes: The instruments were collected and scored by the researcher. 
The administration of the HSCI to the students sampled in the 12 schools in the final sample represented an additional phase of data collection. Arrangements for selection of the course sections to be included in the sample were made in cooperation with the principal of the schools involved. The teachers of the sampled sections were identified, and personal contact was made with these individuals by the researcher. Instructions for administration of the HSCI were relayed to the teachers, and the teachers administered the instrument to students during a class period. The instrument is appropriate for completion by high school students and was completed in a single 50minute class period. The HSCI answer sheets were collected by the researcher and sent to a computer processing center for optical scanning and scoring.

\section{Analysis of the Data}

The Kruskal-wallis one-way aralysis of variance procedure was used to test for the significant differences associated with hypothesis 1 and hypothesis 2 ( $\underline{p}<.05)$. The size of the groups that were compared while in testing for the significant differences associated with these hypotheses was six in all cases. The Kruskal-walis test was used because of the reported appropriateness of this procedure for use with sample sizes ranging from 5 to 10 (Siegel, 1956, pp. 184-186; Roscoe, 1975, pp. 304-305; Wallis \& Roberts, 1965, p. 599). 
Testing of hypotheses 3,4, and 5 was accomplished by determining the Spearman Rank Correlation Coefficient in each instance. The sample size associated with hypothesis 3 was 20 , and the sample size associated with both hypotheses 4 and 5 was six. The Spearman Rank Correlation test was reported to be an appropriate procedure for use with sample sizes ranging from 4 to 30 (Siegel, 1956, p. 211). Tied scores occurred in the data associated with hypotheses 3 and 4 . The spearman procedure was reported to include an effective method for analyzing data including tied scores (Roscoe, 1975, pp. 109-110). Fiedler (1973) also reported that the spearman procedure is appropriate for testing hypotheses similar to hypotheses 3, 4, and 5 of this study.

\section{Organization of the study}

The study was organized into five chapters. The problem of the study, assumptions, definitions, hypotheses, and procedures that were used for collecting and analyzing the data are presented above. Chapter II consists of a review of the literature related to the study. Chapter III presents the data gathered during the study. A discussion of the data is presented in chapter IV. A summary of the study and its implications comprise chapter V. 
CHAPTER II

REVIEW OF RELATED LITERATURE

This review is presented in four major sections. The first section consists of an overview of the literature related to leadexship theory and research. It is followed by a section devoted to literature and research relevant to Fiedler's Contingency Model. Next, there is a description of the high school leadership situation, followed by a chapter summary.

\section{Overview of Leadership Theory and Research}

Numerous classification systems have been used by scholars in an attempt to categorize the various theories of leadership. Stogdill (1974) identified six approaches to the study of leadership. These approaches are (a) great man theories, (b) environmental theories, (c) personalsituational theories, (d) interactional-expectation theories, (e) humanistic theories, and (f) exchange theories. A discussion of theoretical approaches to leadership by Ivancevich, Szilagyi, and Wallace (1977) is conducted within a framework of trait, behavioral, and situational theories of leadership. This overview will be organized according to the following categorization of 
leadership theories presented by Cunning and Gephart

(1973): (a) great man theory, (b) traits theory,

(c) behavioral theory, and (d) situational theory.

The Great Man Theory of Leadership

Early leadership theorists were influenced by an 1879 study by Galton in which he "attempted to explain leadership on the basis of inheritance" (Stogdill, 1974, p. 17). According to William James (1880) the elements that induce creative changes in society are great men. Bass (1960) made the following statement concerning proponents of the great man theory:

The eighteenth century rationalists believed that the personal characteristics of significant figures coupled with good luck determine the course of history. . . . The outstanding exponent of the "Great Man Theory" was Carlyle, who believed a genius would contribute somehow no matter where he was found. (p. 15)

Sherif and Sherif (1953) listed Nietzche and T. S. Eliot among the proponents of the great man theory. Jennings (1960) maintained that "great changes in the history of an organization or society generally result from the innovative efforts of a few superior individuals" (p. 1). A further suggestion made by Jennings was that "the parent of our modern approach to leadersinip is the great man theory" (p. 3).

Stogdili (1974) stated that the great man theorists corcluded that "if the leader is endowed with superior 
qualities that differentiate him from his followers, it should be possible to identify these qualities. This assumption gave rise to the trait theories of leadership" (p. 17).

\section{A Trait Theory of Leadership}

A number of studies made prior to 1940 (e.g., Bernard, 1928; Bogardus, 1934; Fleming, 1935; Wetzel, 1932) attempted to explain leadership in terms of personality traits and character. The identity of significant leadership traits identified in these studies was consistently varied. Bira (1940) reviewed 20 studies which considered 79 traits. He disccvered that only 35\% of the traits identified were mentioned in more than one study. Only four or the traits appeared in five or more studies (Stogdill, 1974) indicated that there was little agreement as to the abilities possessed by leaders.

Stogdill (1948) conducted a review of research studies in which some attempt was made to identify the traits of leaders. Including only traits that were the focus of three or more studies reviewed, Stogdill still reported a list of 29 traits associated with leadership. Stogdill made the following statement concerning this 1948 review:

The items with the highest overall correlation with leadership ard originality, copularity, sociability, judgment, aggressiveness, desire to excel, humor, cooperativeness, liveliness: 
and athletic ability. . . In spite of considerable negative evidence, the general trend of results suggests a low positive correlation between leadership and such variables as chronological age, height, weight, physique, energy, appearance, dominance, and mood control. (p. 67)

The diversity of the evidence and the fact that persons occupy leadership positions in varied situations were emphasized in this review. In regard to the leadership situation, stogdill concluded that the characteristics of the followers bear a relevant relationship to the personal characteristics of the leader. Reporting his views concerning the relationship between changes in the leadership situation and the traits of the leader and followers, Stogdill made the following statement:

The factor of change is especially characteristic of the situation, which may be radically altered by the addition or loss of members, changes in inter-personal relationships, changes in goals, competition of extra-group influences, and the like. The personal characteristics of the leader and of the followers are, in comparison, highly stable. (p. 68)

The trait theory of leadership does not focus attention upon the interpersonal relationships that exist among the leader and members of the group. Ivancevich et al. (1977) commented regarding this limiting factor of the trait theory of leadership:

In addition, focusing on individual traits does not show. what the individual actually does in a leadership situation. Traits identify who the leader is, not the behavioral patterns he or she will exhibit in attempting to influence subordinate actions. The trait approach has 
ignored the subordinate and his or her effect on leadership. Influence is the relationship between two or more people; therefore, focusing on one part only of the influence relationship provides an incomplete view of the leadership process. (p. 277)

\section{Behavioral Theories of Leadership}

The basis of the behavioral theories of leadership

"was the belief that effective leaders utilized a particular style to lead individuals and groups to achieving certain goals, resulting in high productivity and morale"

(Ivancevich et al. 1977, p. 277). Contradictory results of research on leadership traits led to a shift in attention "to a leadership style approach to the theory of leadership" (Johnson \& Johnson, 1975, p. 21). Based upon an earlier experiment by Lewin, Iippitt, and White, an investigation of three leadership styles was conducted by Lippitt and white in the late 1930s and early $1940 \mathrm{~s}$ (Olmsted, 1959, pp. 38-42). The leadership styles studied by Lippitt and white were autocratic, democratic, and laissez-faire.

Although the Lippitt and white studies were an inspiration for other democratic-autocratic leadership studies and writings, stogdill (1974) reported that there is confusion in the iiterature:

Considerable confusion has permeated the literature as a result of the fact that admirers of Lippitt and White research have at times equated democratic leadership with the laissez-faire pattern of behavior. They have claimed for the 
latter form all the results and benefits of the democratic pattern of behavior. (pp. 366367)

After presenting a review of a great number of studies that focused upon democratic-autocratic styles of leadership, Stogdill (1974) provided the following remarks in summary:

The above results clearly indicate that neither democratic nor autocratic supervision can be advocated as a method for increasing productivity, but member satisfaction is associated with a democratic style of supervision. Several studies suggest that satisfaction with supervision differs with the size and conposition of the group. Satisfaction with democratic leadership tends to be highest in small, interaction-oriented groups. Members are better satisfied with autocratic leadership in large, task-oriented groups. (p. 370)

The behavioral approach to the study of leadership was the emphasis of studies conducted at ohio State University during the 1950s. During the course of the ohio state University studies, two independent leadership dimensions were identified. These are "initiating structure" and "consideration." Initiating structure considered the degree to which the leader organized and defined the task. Consideration was defined as behavior that demonstrates a concern for the welfare of group members. The Leader Behavior Description Questionnaire and the Leadership Opinion Questionnaire were developed to measure factors associated with the leadership dimensions under study (Stogdill, 1974, pp. 128-129). 
While the ohio state studies contributed much to the bank of knowledge in the field of leadership theory, the results of the studies were not consistent when conducted in different settings (House, Filley, \& Kerr, 1971). Ivancevich et al. (1977) considered the major criticism of the initiating structure-consideration approach to leadership theory to be "the fact that situational factors and the influence of these factors on leadership effectiveness model were not considered" (p. 279).

\section{Situational Theories of Leadership}

In his 1948 review of the literature, Stogdill analyzed 124 studies which indicated that patterns of leadership traits differed as the situation was changed. Terman's 1904 study was given by stogdill as an illustration of an early study detecting effective leadership traits in varied situations. Stogdill reported Terman's finding that children who are leaders in one situation may not be the group leader when placed with different children in other settings. A study conducted among groups of boys by Hare (1957) indicated that self-oriented and group-oriented leaders do not differ in aggression on the school's playground, but self-oriented leaders are more aggressive in the neighborhood.

Hemphill. (1949) described groups in terms of 15 variables in conjunction with a study of the situational 
element in leadership. Hemphill found that leadership effectiveness is most highly correlated with the group members' satisfaction with the group and the cohesiveness existing in the group (p. 33). The general trend of the research reviewed by stogdill (1974) supports the hypothesis that groups tend to accept as leaders those persons who exhibit characteristics and talents that will facilitate the accomplishment of the group's specific task ( $p$. 169).

Fiedler (1967) identified three situational variables that interact with the leader's behavior in determining the effectiveness of a leadership style: task structure, group atmosphere, and leader's position power. Chemers and Rice (1974) reported that Fiedler's approach to leadership theory "stands at the center of an important and growing interest in contingency theories of leadership" (p. 91).

\section{Fiedler's Contingency Model}

As previously pointed out, no single personality trait or leadership style has been consistently related to effective leadership. Fiedler (1967) advanced the following notion:

The effectiveness of a group is contingent upon the relationship between leadership style and the degree to which the group situation enables the leader to exert influence. (p. 15) 
In addition to integrating the existing theories of leadership, Fiedler's Contingency Model focuses on groups existing in natural settings. Fiedler (1967) indicated that less than 5\% of the studies he reviewed dealt with groups in a natural setting. He made the following remarks concerning the appropriate context for group leadership research and theorizing:

This means that most data about small groups, and the theories which are based on them, are derived from a highly selected and unrepresentative sample of the teams which are found in the real world. (p. 17)

Fiedler and Chemers (1974) submit that the contingency model is appropriate for providing an adequate explanation of "the full range of leadership phenomena" ( $p$. 11).

\section{Overview of the Contingency Model}

Four factors serve as the framework for Fiedler's Contingency Model: (a) leadership style assessment, (b) task structure, (c) group atmosphere, and (d) the leader's position power. The contingency model was developed within the context of this framework.

Leadership style. The leadership style of a person is measured by use of an instrument developed by Fiedler (1967) called the Least Preferred Coworker (LPC) scale (pp. 36-60). The respondents are asked to describe the person with whom they could work least well. This least preferred co-worker is to be described as a composite of 
all co-workers one has ever had. The description is made by rating that person on a simple bipolar scale. The LPC score is obtained by totaling up point values for all the items. A low score indicates that an individual is oriented toward rejecting those who are least preferred as fellow-workers. The lower the score, the greater the task orientation of the leader. A high LPC person perceives both good and bad attributes in the least preferred co-worker. This person is more motivated to use a relationsoriented leadership style.

The basic goal of the high LPC leader is to maintain favorable relations with other persons. If the high LPC leader reaches this goal, the leader then strives to reach the secondary goals of status and esteem. These goals call forth the need to be admired and recognized (Fiedler \& Chemers, 1974, p. 76).

The low LPC leader has a different motivational system. Task accomplishment is this person's basic goal. Self-esteem is gained through achievement of task related goals. As long as the goal of task accomplishment presents no difficulties, this type of leader tends to be friendly and pleasant when relating to subordinates. If the accomplishment of the task is threatened, good interpersonal relations assume an importance secondary to accomplishing the task. 
Task structure. The task structure is defined as the degree to which the group task is routine or complex. The components of the task structure include: (a) goal clarity, (b) goal-path multiplicity, (c) decision verifiability, and (d) decision specificity (Fiedler \& Chemers, 1974, p. 67). Groups engaged in routine tasks are likely to have clearly defined goals and output that can be easily evaluated. They generally are involved in jobs that can be solved in a few steps and in problems having only one correct solution.

In more complex task situations, the goals are less clear, and the method of accomplishing the task may vary from situation to situation. The task is also difficult to monitor while in progress, and there may be several acceptable solutions to problems.

Group atmosphere. This element of the contingency model is defined as the degree of confidence, trust, and respect subordinates have in the leader. Fiedler (1967) identified this factor as leader-member relations (p. 158). A method for identifying leader-member relations is the Group Atmosphere (GA) scale. This scale is completed by the leader. A high GA score indicates that good leadermember relations exist, and a low GA score suggests that the relationship between the leader and subordinates is poor (Fiedler \& Chemers, 1974, p. 65). The more friendly the relationship between the leader and followers, the 
easier it is for the leader to obtain group cooperation and effort. When a poor relationship exists between the subordinates and the leader, the leader may have to resort to special favors to get good performance.

Position power. Position power is defined as the extent to which the leader possesses a legitimate power base. A common way in which power is vested in the leader is by providing him with the right to direct, evaluate, and reward and punish those he is asked to supervise. Fiedler \& Chemers (1974) assumed that most managers have high position power, and "in most situations, the subordinates have a clear idea of the leader's legitimate authority, and only rarely is this authority seriously challenged" (p. 68).

Development of the contingency model. Beginning in 1951 at the University of Illinois, Fiedler and his associates conducted a 12-year study of over 800 groups. The findings of these studies served as the theoretical base upon which the contingency model was constructed. Basketball teams, policy-making groups, consumer sales cooperatives, bomber crews, and management teams were among those selected as experimental subjects by Fiedler (1967) and his associates. These groups were selected for study because in these group settings, "the members had to interact and coordinate their efforts to achieve a common goal" (Fiedler \& Chemers, 1974, p. 79). 
Objective performance criteria, which reflected the major assigned goal of the group, were used wherever possible. The groups selected for scudy also reflected the spectrum of leadership styles and leadership situations Fiedler (1967) predicted as being influential in group effectiveness in accomplishing goals (p. 61).

Fiedler (1967) reported the notion that the effectiveness of a group is contingent upon the relationship between the leadership style of the group's leader and the nature of the leadership situation (p. 15). According to Fiedler, three elements comprise the leadership situation: (a) task structure, (b) the leader's position power, and (c) group atmosphere. Fiedier further categorized the leadership situation into eight categories that he labeled octant 1 through octant 8. Fiedler and his associates classified and analyzed the data gathered during their extensive studies in a manner consistent with the eight octants model of leadership effectiveness.

Table I shows the correlations between leader LPC scores and group effectiveness predicted for each octant by the contingency model presented by Fiedler (1967, pp. 133-146). The octant number, three situational variables, and predicted correlation are shown in the columns of this table. The octants are arranged in order of the favorabieness of the leader situation, from most favorable to least favorable. According to Fiedler's 
Contingency Model a leader will have the most control and influence in groups that fall into octant 1 . In this first octant the leader is accepted, has high position power, and leads a group performing relatively structured tasks. The leader's control and influence decrease from octant 1 through octant 8 .

Table 1

Predicted Correlations Between Leader LPC Scores and Group Effectiveness According to Fiedler's Contingency Model

\begin{tabular}{lllll}
\hline Octant & $\begin{array}{c}\text { Group } \\
\text { atmosphere }\end{array}$ & $\begin{array}{c}\text { Task } \\
\text { structure }\end{array}$ & $\begin{array}{c}\text { Leader } \\
\text { position } \\
\text { power }\end{array}$ & $\begin{array}{c}\text { Predicted } \\
\text { correlation }\end{array}$ \\
\hline 1 & good & $\begin{array}{l}\text { structured } \\
\text { structured }\end{array}$ & $\begin{array}{l}\text { strong } \\
\text { weak }\end{array}$ & -.52 \\
3 & good & unstructured & strong & -.33 \\
4 & good & unstructured & weak & .47 \\
5 & good & structured & strong & .42 \\
6 & poor & structured & weak & .20 \\
7 & poor & unstructured & strong & .05 \\
\hline & poor & unstructured & weak & -.43 \\
\hline
\end{tabular}

A negative correlation between leader LPC scores and group effectiveness predicts that iow LPC leaders perform better than high LPC leaders. Positive correlations between these same variables indicate that high LPC leaders will be most effective (Fiedler, 1967, pp. 270-271).

Fiedler and Chemers (1974) provided the following summary of the major hypothesis emerging from the contingency model: 
The Contingency Model leads to the major hypothesis that leadership effectiveness depends upon the leader's style of interacting with his group members and the favorableness of the group-task situation. Specifically, low LPC leaders who are primarily task-motivated perform best under conditions that are very favorable or very unfavorable for them. Relationship-motivated leaders perform best under conditions that are of moderate favorableness. (p. 81)

Overview of Literature Related

to the Contingency Model

Organizational climate. Feidler (1967) did not use the term "organizational climate" in identifying the elements of the leadership situation associated with the contingency model. In a 1974 discussion of the leadership situation, Fiedler and Chemers emphasized the concept of organizational climate and described the concept as representing the "interpersonal aspects of the situation" (p. 57). The organization's character "is often referred to as the organizational climate" (Hellriegel \& Slocum, 1976, p. 11). Lewin (1951) used the concept of friendly, tense, and hostile to describe dimensions of the group climate or atmosphere. In characterizing the study of behavior, Lewin stated that the general characteristics of the atmosphere are as important to human behavior as is "the field of gravity for the explanation of events in classical physics" (p. 240).

McGregor. (1960) made the following statement related to the nature of organizational climate: 
The day-by-day behavior of the immediate superior and of other significant people in the managerial organization communicates something about their assumptions concerning management which is of fundamental significance. . . Many subtle behavioral manifestations of managerial attitude create what is often referred to as the "psychological climate" of the relationship. (pp. 133-134)

Various dimensions of organizational climate have been studied. Halpin and Croft (1962) studied different aspects of organizational climate, leadership, and group member behavior within schools. These researchers classified organizational climate along an open-closed continuum. Halpin and croft found that an open climate provides for esprit if the leader is hardworking. An aloof leader provides for group member disagreement within a closed climate. The findings of Halpin and croft "suggest that the type of leadership in a group and the responses of the followers are related to various characteristics of the group itself" (Stogdill, 1974, p. 237).

Likert (1961) studied authoritative and participative management systems. He compared the several aspects of the organizational climate as perceived by members of the organization. Likert suggests that there is a causal relationship between the type of management control directed toward the group and the morale and success level perceived by group members (pp. 223-233).

Etzioni (1964) described the social interactions of persons within organizations in terms of exchange, conflict, 
cooperation, and bargaining (pp. 111-112). Elaborating on Etzioni's construct, Hill (1972) discussed the organizational climate in terms of a conflict-cooperation continuum. Hill stated that even though personal interactions affect the members of organizations, "it is not clear whether cooperative relationships have positive or negative consequences for the recipients of the organization's actions" (p. 323). While evidence has been presented that indicates a reduction of labor turnover and an increase in employee satisfaction can be enhanced by a cooperative organizational climate, a cooperative climate does not tend to increase group effectiveness (Bayfield \& Crockett, 1955; Csoka, 1972). Fiedler and Chemers (1974) advocate the notion that the organizational climate will interact with the leader's style, but they argue that "there is very little empirical evidence from field studies that one type of climate is necessarily more conducive to effective organizational performance than another" (p. 110).

Validation of the model. Fiedler's Contingency Model of Leadership Effectiveness has been tested in numerous field and laboratory studies. Hunt (1967) conducted a ficld study of the contingency model in the following three settings: (a) a large physical science research laboratory, (b) a heavy machinery plant, and (c) a supermarket chain. Hunt's study confirmed the validity of the contingency 
model for octants $1,3,5$, and 7 . The remaining four octants were not tested in this study.

Fiedler (1971) reported the results of two studies conducted among groups of public health volunteers. A 1966 study conducted by Fiedler, O'Brien, and Ilgen and a 1968 study directed by O'Brien are included in this report. The contingency model was tested in octants $1,4,6$, and 8 by these studies. The median correlations reported for these two studies support the model, with the exception of octant 6 findings. A correlation between LPC scores and group performance of .67 was reported in the 1966 study. This variation from correlations predicted by the contingency model was not found in the 1968 study (Fiedler, 1971). A validation study was conducted by Shima in 1968. This study was conducted among 32 groups of Japanese high school students. Fiedler (1971) analyzed the findings of Shima and classified the leadership situation of this study as corresponding to octants 2 and 4 . The corresponding correlations were -.26 and .71 , "thus supporting the model" (Fiedler, 1971, p. 136). Fiedler (1971) reported in a 1969 study in which Skrzypek conducted a test of the contingency model among all eight cells. Subjects for this study were selected from a group of West point cadets whose LPC scores fell either one standard deviation above or below the mean. Structured and unstructured tasks were contrived for the groups to accomplish. Skryzpek reported 
that none of the correlations was significant $(\underline{p}<.05)$. With the exception of octant 3 , the correlations did all represent the positive or negative directions predicted by the contingency model.

Chemers and Skrzypek (1972) conducted another study at west point. The methodology used in this study was essentially the same as that employed by Fiedler (1967) except that instead of relying on post hoc measures of group atmosphere, leader-member relations were independently manipulated in the experiment. The leaders in the low power situation were instructed to act as chairmen, and the group was told that the leader had no real power to reward or punish group members. In the high power situation, groups were informed that it was the leader's responsibility to evaluate the performance of each group member and assign a score which would become part of the cadet's service record. The manipulations employed by the experimenters yielded the complete octant spectrum present in the contingency model. When the resultant correlations were plotted against the curve predicted by the contingency model, a close agreement between the two curves was reported by Chemers and Skrzypek. The rank order correlation between predicted and obtained curve points was .86 ( $\underline{p}<.05)$. Chemers and Rice (1974) make the following comment regarding this study: 
The Chemers and Skrzypek (1972) study, by nature of its clean methodology and strong results, provides extremely powerful support for the contingency model curve. It establishes the predictive validity of the model and indicates that experimental studies of leadership can be quite useful. (p. 104)

In an analysis of four field studies conducted between 1967 and 1969, Fiedler (1971) reported that the median correlations for field studies are quite similar to those predicted by the contingency model. The medians were reported to all be in the predicted direction, and 13 of the 15 specific correlations found were in the expected direction $(\underline{p}<.05)$. Fiedler (1973) presented the following argument in defense of a charge that field studies focusing on less than the full spectrum of the contingency model are inadequate validity support for the model:

One can hardly ask basketball teams, open-hearth steel crews, or grocery department employees to drop what they are doing in order to work on creative unstructured tasks under leaders whose position power is variously low or high. Nor could we ask a chemical research team or boards of directors to play a quick game of basketball or to operate a meat market. . . (p. 364)

Criticism of the model. Fiedler (1967) conducted a large field experiment conducted in conjunction with the Belgian naval forces. The study included 96 three-man teams. The teams were assembled so that 48 teams would be culturally homogeneous and 48 teams, heterogeneous. Homogeneous teams were comprised of members who spoke the same language. This language factor is a key element of the 
critical argument made by Graen, Alvares, Orris, and Martella (1970) concerning this study. Graen et al. claimed that this language variable added a variable to the research design that presented a 16-cell experimental model. These critics argue that a 16 -cell model is inappropriate for testing the 8-cell contingency model.

Fiedler (1967) conducted an analysis of the experimental data gathered from the heterogeneous groups in terms of an 8-cell model. In a discussion concerning the complete analysis of the data gathered during this study, Fiedler (1967) stated that "while only one of the sixteen correlations was significant, only one of the eight correlations, namely, .03, was not in the hypothesized direction" (p. 119). Graen et al. (1970) took issue with Fiedler's assessment of the correspondence of correlations to the hypothesized direction being "employed as an alternative criterion of reliable results" (p. 289).

In a more elaborate explanation of their viewpoint concerning the statistical validity of Fiedler's conclusions, Graen et al. commented as follows:

The danger in rejecting the usual criterion of statistical reliability is that we may be forced into generating empirically most of the sampling distribution of our statistic under the null hypothesis before we can accept that hypothesis. . . (p. 289)

A 1969 study conducted by Mitchell was cited by Graen et al. as an additional illustration of the questionable validity of the contingency model. Summarizing their 
presentation of the findings of this study, Graen et al. (1970) stated, "It should be noted that the curve generated by plotting the median correlation for each octant is opposite that predicted by the contingency model" (p. 291). Ashour (1973) presented a critical review of the contingency model. He was also critical of Fiedler's process of accepting correlationsobtained in the predicted direction regardless of whether or not these statistics were statistically significant. Ashour argued that the model lacks validity since it was generated from a broad sampling of settings and procedures. Each of these early formative studies dealt with no more than two octants. Ashour made the following comment regarding these early studies:

The limited representation of the octants raises the possibility that the data obtained could merely be a function of the populations sampled rather than reflecting true differences between octants. (p. 348)

Yunker (1973) field tested the contingency model of leadership effectiveness. The study was limited to a test of two octants of the model. The subjects of the investigation were 780 presidents and members representing 62 collegiate chapters of a national business fraternity. Yunker's findings did not support Fiedler's Contingency Model in the two octants tested. The researcher in this instance suggested that the methods used by Fiedler to measure the situational dimension of the contingency model may be unnecessarily complex. Yunker derived a simplified 
measure of the situational favorableness. This revision produced findings that strongly supported the model in the two octants sampled.

An investigation of the application of the contingency model has been conducted by Mellor (1974) in the elementary school setting. The effectiveness of the principal's performance in each school sampled was determined by measures of student academic achievement and school environment. Mellor reported that the student achievement measures were controlled for intelligence quotient, socioeconomic status, and race. The 44 schools participating in the study were classified into four octants of the contingency model. In an analysis of the data gathered, Mellor found no significant correlations between principal's LPC scores and student achievement $(\underline{p}<.05)$. Correlations between the principal's LPC score and school environment were also not found to be significant $(\underline{p}<.05)$. These correlations in octants 5 and 7 were reported to be in the opposite direction of that predicted by the contingency model. Mellor concluded that the contingency model does not provide a reliable basis for predicting the relationship between leadership style and group effectiveness in the operational setting corresponding to this study.

Many of those critical of the contingency model have suggested that modifications and extensions be made to the model (Ashour, 1973; Graen et al., 1970; Yunker, 1973). 
Commenting on the practice of extending and modifying the contingency model, Fiedler (1971) made the following statement:

Some investigators. . . have not followed the methodology originally described. . . . These differences in methodology and divergencies from the model are, of course, quite appropriate and desirable. (p. 132)

Extensions of the model. Fiedler (1971) reported a 1966 study by Shaw and Blummer in which leadership behavior was varied under experimental conditions. Nine leaders were instructed to behave in a highly controlling and directing manner, while a second set of nine leaders was told to be passive and permissive. This test of the contingency model used the leaders' LPC scores but did not include the GA measure since the leader-member relations element was experimentally manipulated. The results of this test of octants 2 and 4 of the contingency model "conform to the general expectations of the model" (Fiedler, 1971, p. 141).

Bell (1970) applied the contingency model to co-acting groups among 43 institutions within the North Carolina Community college system. The institutions were classified and grouped into the octant which described the particular leadership situation. Correlations were run between LPC scores of the leaders and the group cffectiveness measures. Bell reported findings that significantly conformed with Fiedler's Contingency Model. The rescarcher concluded that this study presents evidence for the argument that the 
contingency model is applicable to groups in which members co-act. In a co-acting group, members act in relative independence from theirco-workers as group goals are accomplished.

Fiedler (1971) reported a 1967 study by Lawrence and Lorsch in which leader-member relations were not included in the research design. The performance of six chemical processing companies was compared during this study. Four subsystems were present within each of these organizations: (a) production, (b) sales, (c) applied research, and (d) basic research. The structure of these subsystem units was rated and used as a basis for predicting the leadership situation. The experimenters found "that a low LPC manager would perform better in a structured situation, while a high LPC manager would perform better in unstructured situations" (Fiedler, 1971, p. 142). These researchers suggested that the leader-member relations might be less important at the higher levels of an organization. Fiedler (1971) made the following statement in reference to this view of leader-member relations:

This seems reasonable since the manager at the third and higher levels usually has very few direct contacts with production workers at the non-supervisoy levels, and relatively few contacts with first-line supervisors. (p. 142)

A field study conducted by Garland and O'Reilly (1976) represents another extension of the contingency model. These researchers constructed a factorial research design 
that identified combinations of high, intermediate, and low LPC principals and high and low GA scores and assigned the combinations to the appropriate design cells. Garland and O'Reilly expressed an interest in Likert's theories that challenge the implied independence of the leadership style and situational favorability factors of Fiedler's contingency Model. Garland and O'Reilly (1976) made the following remarks in relation to this point:

According to likert, the process of activity in an organization can be conceptualized in terms of causal variables (e.g., leadership style) and intervening variables which, in turn, predict end-result variables. . . . (p. 14)

While the $F$ ratios for two of the null hypotheses formulated by Garland and O'Reilly were not significant, it was reported that the performance of good-group-atmosphere staff groups led by high, intermediate, and low LPC principals differed significantly from that of poor group atmosphere groups led by intermediate LPC principals $(\underline{F}(7.37)=3.80 ; \underline{p}<.01)$. The null hypothesis that was rejected was designed to test the impact of group atmosphere on group performance. The researchers concluded that while the contingency model has proved to be quite powerful, this study showed that those principals who had worked with staffs for over two years and had "enjoyed good leader-member relationships, ran good schools" (Garland \& O'Reilly, 1976, p. 27). The researchers further describe their extended study of the contingency model as an 
initial effort toward integrating two useful theories of leadership.

Hunt (1971) extended the contingency model to an organizational setting having two managerial levels. The study was conducted among 26 teams, each headed by an executive in a simulated organization. All teams were assigned complex problems. Each team was comprised of two interdependent sections. Both sections were headed by a manager, the leader of the second level of management in the organization. The teams were grouped into four executive-manager leadership-style combinations according to LPC scores. After analyzing the relationship between LPC scores of the executive and the manager and team performance, Hunt remarked:

Specifically, executives with low LPC scores and managers with high LPC scores had the best performing groups while the poorest performing groups were found with executives with high LPC scores and managers with low LPC scores. (p. 483)

Description of the High School Leadership Situation

The high school principal occupies the position of a designated leader of a team of individuals organized to conduct the administrative processes necessary for accomplishing the goals of the school.

\section{Position Power}

The principal of a high school has the responsibility 
of organizing and administering the human and physical resources "efficiently and effectively so that the school objectives can be successfully achieved" (Gorton, 1976, p. 43). Among the activities of the high school principal are the tasks of (a) recruiting and recommending qualified personnel for employment, (b) supervising and evaluating the performance of staff members, (c) stimulating the professional growth of staff personnel, (d) leading the staff in the formulation of instructional objectives, and (e) making decisions concerning the curriculum organization and content (Chernow \& Chernow, 1976; Corbally, Jensen, \& Staub, 1961; Gorton, 1976). The principal of a high school is an established designated leader of the organization. The person associated with the title "principal" is responsible for the implementation of district policy within the high school (Landers \& Myers, 1977, p. 5).

A checklist was developed by Hunt (1967) for use in determining the leader position power in organizations. An application of the 12 items in Hunt's checklist places the position power of the high school principal high on the scale (Fiedler \& Chemers, 1974, p. 133; Garland \& O'Reilly, 1976).

Structure of the Group Task

As previously stated, the tasks of the administrative team are complex and varied (Campbell, Bridges, \& Nystand, 
1977, pp. 116-149). In 1968 McNamara conducted a study among high schools and determined that while the tasks of elementary schools were largely structured, the tasks of high schools were primarily unstructured (Fiedler \& Chemers, 1974). Garland and O'Reilly (1976) also found that the task structure of high schools can be appropriately classified as unstructured. Fiedler and chemers make the following summarizing statement concerning the task structure and position power of the high school principal:

The schools are fairly large. . . and the principal has to deal with teenagers who are notoriously difficult to handle. Moreover, the secondary school principal generally has to interact with various civic, governmental, and parent organizations, and he must make policy on a variety of questions which arise. Thus, although he has moderately high position power, his task is likely to be unstructured. . . (p. 133)

\section{Chapter Summary}

The study of leadership has been categorized in this review into four approaches to leadership theory: (a) great man, (b) trait, (c) behavioral, and (d) situation. Research efforts were focused upon the behavioral and situational approaches to leadership theory, as conflicting evidence became associated with great man and trait theoretical studies of leadership (Stogdill, 1974). The situational approach to leadership, as described in this discussion, includes the leadership style element of the behavioral 
approach but adds the situational dimension to the theoretical construct.

Fiedler (1967) advanced the theoretical construct that leadership effectiveness is dependent upon both the leader's style of leadership and the group leadership situation. The contingency model developed by Fiedler includes the following four factors that describe the leader and the leadership situation: (a) leadership style, (b) task structure, (c) group atmosphere, (d) position power.

The contingency model Fiedler developed was the result of 12 years of study with 800 laboratory and field study groups. The model can be graphically represented in terms of eight cells that represent combinations of the leadership situation variables and a corresponding listing of group performance correlated with LPC score.

The interpersonal relations among the members of organizations have been identified as a significant aspect of the leadership situation (Fiedler \& Chemers, 1974). Lewin (1951), McGregor (1960), Halpin and Croft (1962), and Likert (1961) stressed the significance of the group climate. Likert suggested that a causal relationship exists between the behavior of leaders and the organizational climate perceived by the nembers of the organization. Bayfield and crockett (1955) reported that a cooperative climate, generally viewed as advantageous, does not tend to enhance increased group performance. 
Numerous studies have been conducted as validations of the predictable power of the contingency model. The laboratory and field studies that have been reported tend to support the contingency model (Fiedler, 1971). A study reported by Chemers and Skrzypek (1972) identified evidence that supported the contingency model's predictive power over al1 eight cells.

Criticism has been leveled at the contingency model on a number of occasions over several issues. The methodology employed by Fiedler (1967) in the Belgian Navy experiment was challenged by Graen et al. (1970). Fiedler's practice of accepting correlations that are not statistically significant as evidence for validation of the contingency model is also questioned by Graen et al. Ashour (1973) was critical of the many experiments encompassing only a few of the octants of the model that are cited as validation evidence by Fiedler.

Among the studies extending the contingency model are those reported by Bell (1970), Fiedler (1971), Garland and O'Reilly (1976), and Hunt (1971). These studies do represent a variety of research designs, but the researchers were all able to successfully predict a substantial number of findings. These predictions were based upon the theoretical principles associated with the contingency model. 
The leadership situation in large high schools has been identified as one in which the position power of the principal is high and the group task is relatively unstructured (Fiedler \& Chemers, 1974). This description of the leadership situation within a large high school is consistent with the leadership situations described by octants 3 and 7 of the contingency model developed by Fiedler (1967, p. 121). 
CHAPTER III

PRESENTATION OF THE DATA

The focus of this study was upon the interrelationships among leadership style, organizational climate, and group effectiveness. The data were collected in two phases as described in the procedures section of the study. During the initial phase of data collection, the Least Preferred Coworker (LPC) scale was administered to the 20 participating high school principals. The principal and all other members of the administrative teams selected for this study also completed the Group Atmosphere (GA) scale during this phase.

An analysis of the data gathered during the initial stage of this study was conducted to identify the subjects for the final stage of the investigation. Students from the 12 schools identified for this final sample were administered the High School Characteristics Index (HSCI) according to the procedures previously stated.

During the course of the analysis of the data related to the problem, the five null hypotheses associated with the research questions stated in chapter I were tested. 


\section{Initial Phase Data}

\section{Leadership Style Data}

The principals of the 20 schools selected as research subjects completed the LPC scale. Scoring of the principals' LPC responses was accomplished according to procedures described by Fiedler (1967, p. 44). The LPC scores are listed in Table 2 along with the fictitious names of the selected schools. The schools are listed in decreasing order of IPC scores.

\section{Table 2}

Least Preferred Coworker Scores of the Principals

\begin{tabular}{lc}
\hline \multicolumn{1}{c}{ School } & $\begin{array}{c}\text { Least Preferred } \\
\text { Coworker score }\end{array}$ \\
\hline Space High & 119 \\
Central High & 107 \\
Palm High & 96 \\
Redwood High & 93 \\
Beach High & 87 \\
Champion High & 87 \\
Southern High & 87 \\
Pioneer High & 82 \\
Sand High & 70 \\
Union High & 70 \\
Coast High & 68 \\
Lakeside High & 65 \\
Summer High & 61 \\
Ocean High & 55 \\
High Banks High & 51 \\
Fern High & 50 \\
Westbrook IIigh & 50 \\
Northern High & 47 \\
Highland High & 38 \\
Pine Ridge & 34 \\
\hline
\end{tabular}


The reader will recall from the discussion in Chapter I that a high LPC score indicates a relationship-motivated style of leadership (low task motivation), whereas a low LPC score is indicative of a task-motivated leader. The highest score among the 20 principals was 119 . The lowest score was 34. The mean score for the total group was 70.85 .

Posthuma (1970) studied the responses of 2,415 individuals to the LPC scale. The individuals Posthuma selected as research subjects were engaged in a diverse range of leadership roles. Posthuma reported that the mean LPC score was 59. Although the mean LPC score that was reported for this study is greater than that reported by posthuma, this difference is to be expected. It is likely that high school principals will indicate higher LPC scores (be more relationship oriented) than a sample of leaders selected from the normal population (Garland \& O'Reilly, 1976). Halpin (1966) also presented data that are consistent with the data reported for this study. Halpin concluded that school administrators are more relationship motivated than are some other groups of administrators (pp. 99-111).

As stated in the definition of terms section of Chapter I, principals who indicated a score of 70 or above on the LPC scale were classified as relationship-motivated (high LPC) leaders. Principals scoring below 70 on the LPC scale were classified as task-motivated (low LPC) leaders. 
These classifications are consistent with the definitions given by Fiedler (1967, p. 44).

A survey of the LPC scores listed in Table 2 shows that 10 principals scored 70 or above on the LPC scale and 10 principals scored less than 70 on the LPC scale. Therefore, according to the leadership style classification definitions established for this study, 10 of the participating principals were classified as high LPC leaders, and the remaining 10 were classified as low LPC leaders.

\section{Organizational Climate Data}

Members of the selected high school administrative teams, including the principals, completed the GA scale. Usable scales were scored as Fiedler (1967) directed (p. 116). School names, the number of members in each administrative team, usable number of GA scale forms obtained, and the mean GA scores are listed in Table 3 . Table 3 shows the GA scores listed in descending order. The mean GA scores ranged from a high score of 79.333 to a low score of 61.500 . The mean score for the total group of GA scores was 72.281. Posthuma (1970) studied the responses of 2,415 subjects on the GA scale and reported that the mean GA score for ficld study groups was 64.9. Although the mean score for the total group of GA scores for this study was substantially greater than that determined by Posthuma, the range of the scores was 
sufficient to allow an effective differentiation between high and low GA groups when these data was used (Chemers \& Skrzypek, 1972; Fiedler \& Chemers, 1974).

Table 3

Administrative Team Membership and Mean GA Scores

\begin{tabular}{lrcc}
\hline School & $\begin{array}{c}\text { Administrative } \\
\text { team membership }\end{array}$ & $\begin{array}{c}\text { Number } \\
\text { of usable } \\
\text { instruments }\end{array}$ & $\begin{array}{c}\text { Mean GA } \\
\text { score }\end{array}$ \\
\hline Fern High & 9 & 9 & 79.333 \\
Highland High & 16 & 16 & 77.118 \\
Westbrook High & 9 & 9 & 76.889 \\
Sand High & 8 & 8 & 76.875 \\
Redwood High & 10 & 10 & 75.900 \\
Palm High & 8 & 8 & 75.375 \\
High Bank High & 12 & 12 & 75.300 \\
Beach High & 10 & 10 & 74.399 \\
Pine Ridge High & 12 & 12 & 74.333 \\
Lakeside High & 11 & 12 & 72.273 \\
Champion High & 15 & 10 & 71.600 \\
Central High & 10 & 10 & 70.889 \\
Union High & 10 & 9 & 70.778 \\
Northern High & 9 & 15 & 70.706 \\
Pioneer High & 15 & 10 & 70.455 \\
Ocean High & 11 & 9 & 70.222 \\
Space High & 9 & 13 & 65.539 \\
Summer High & 13 & 12 & 63.999 \\
Southern High & 12 & 16 & 61.500 \\
Coast High & 16 & & \\
\hline
\end{tabular}

Selection of Final Sample

The administrative teams that participated in this study, and shown in Table 3, were assigned a rank order number consistert with the mean GA score indicated by each team. This rank order listing is shown in Table 4. Fern High School was ranked first and coast High School last. 
The final selection of schools was based on these findings.

Table 4

Rank Order of Schools According to Mean GA Scores

\begin{tabular}{|c|c|c|c|}
\hline $\begin{array}{c}\text { Rank order } \\
\text { number }\end{array}$ & $\begin{array}{l}\text { Name of } \\
\text { school }\end{array}$ & $\begin{array}{c}\text { Rank order } \\
\text { number }\end{array}$ & $\begin{array}{l}\text { Name of } \\
\text { school }\end{array}$ \\
\hline 1 & Fern High & 11 & Champion High \\
\hline 2 & Highland High & 12 & Central High \\
\hline 3 & Westbrook High & 13 & Union High \\
\hline 4 & Sand High & 14 & Northern High \\
\hline 5 & Redwood High & 15 & Pioneer High \\
\hline 6 & Palm Ifigh & 16 & Ocean High \\
\hline 7 & High Banks High & 17 & Space High \\
\hline 8 & Beach High & 18 & Summer High \\
\hline 9 & Pine Ridge High & 19 & Southern High \\
\hline 10 & Lakeside High & 20 & Coast High \\
\hline
\end{tabular}

The administrative teams with the six highest mean GA scores and the six lowest mean GA scores were selected for the final sample. Those administrative teams indicating the six highest GA scores were labeled the most cooperative climate group. The administrative teams indicating the six lowest GA scores were labeled the least cooperative climate group.

Table 5 shows the most cooperative (high GA) and least cooperative (low GA) administrative teams listed by school name. The schools are listed in descending order of GA score within both the high GA and low GA group categories. 
Table 5

Mean GA Scores Indicated by Administrative Teams in Final Sample

\begin{tabular}{cc}
\hline Schools & Mean GA score \\
\hline $\begin{array}{c}\text { Most cooperative } \\
\text { schools (high GA) }\end{array}$ & \\
Fern High & 79.333 \\
Highland High & 77.118 \\
Westbrook High & 76.889 \\
Sand High & 76.875 \\
Redwood High & 75.900 \\
Palm High & 75.375 \\
& \\
Least cooperative & \\
schools (low GA) & \\
Pioneer High & \\
Ocean High & 70.706 \\
Space High & 70.455 \\
Summer High & 70.222 \\
Southern High & 65.539 \\
Coast High & 63.999 \\
\end{tabular}

The mean GA scores within the most cooperative group ranged from a high of 79.333 to a low score of 75.375 . The highest score was indicated by the Fern High administrative team, and Palm High's administrative team indicated the lowest. The mean of the total mean GA scores reported for the most cooperative group was 76.915 , and the mean determined for the total mean Ge scores in the least cooperative group was 67.070

The organizational climate factor for this study was measured by having all members of the administrative teams 
participating in the study complete the GA scale. Fiedler (1967) had only the leader complete the GA scale as the leader-member relations were measured. This deviation from Fiedler's original methods was made to measure the opinions of team members concerning the quality of the relationship between group members and the principal and the relationship among all team members. This approach was taken in part due to the support that Fiedler and Chemers (1974) gave to a 1972 study conducted by csoka in which all group members were included in the measurement of leader-member relations (p. 111). Table 6 shows the GA scores reported by the principals in this study and the mean GA group scores. The scores are listed according to the descending order of mean GA group scores. The mean GA rank order number previously discussed is also included in Table 6 . Principal GA scores ranged from a high of 80 to a low of 54. The mean principal GA score was 71.2. The principals of three high schools, Fern, Highland, and Westbrook, indicated the highest principal GA score listed. The principal of space High indicated the lowest principal GA score listed. A study of the principals' GA scores among the six high schools ranked 1 through 6 and the six high schools ranked 15 through 20 according to mean group GA scores presents a finding of interest. The data listed in Table 6 show that if either the mean GA scores or the principals' GA scores are used for ranking the schools 
according to climate ratings, the same schools would be included in the group ranked 1 through 6 and the group ranked 15 through 20. Hence, the same schools would be assigned to the most cooperative and least cooperative groups that comprised the final sample if either principal GA or mean group GA scores were used.

\section{Table 6}

Principal GA Scores and Mean Group GA Scores

\begin{tabular}{|c|c|c|c|}
\hline School & $\begin{array}{l}\text { Principal } \\
\text { GA score }\end{array}$ & $\begin{array}{c}\text { Mean GA } \\
\text { rank order } \\
\text { number }\end{array}$ & $\begin{array}{l}\text { Mean group } \\
\text { GA score }\end{array}$ \\
\hline Fern High & 80 & 1 & 79.333 \\
\hline Highland High & 80 & 2 & 77.118 \\
\hline Westbrook High & 80 & 3 & 76.889 \\
\hline Sand High & 75 & 4 & 76.875 \\
\hline Redwood High & 76 & 5 & 75.900 \\
\hline Palm IIigh & 77 & 6 & 75.375 \\
\hline High Banks High & 70 & 7 & 75.300 \\
\hline Beach High & 70 & 8 & 74.399 \\
\hline Pine Ridge High & 72 & 9 & 74.333 \\
\hline Lakeside High & 70 & 10 & 72.273 \\
\hline Champion High & 70 & 11 & 72.133 \\
\hline Central High & 71 & 12 & 71.600 \\
\hline Union High & 70 & 13 & 70.889 \\
\hline Northern High & 70 & 14 & 70.778 \\
\hline Pioneer High & 69 & 15 & 70.706 \\
\hline Ocean High & 68 & 16 & 70.455 \\
\hline Space High & 54 & 17 & 70.222 \\
\hline Summer High & 67 & 18 & 65.539 \\
\hline Southern High & 66 & 19 & 63.999 \\
\hline Coast lligh & 69 & 20 & 61.500 \\
\hline
\end{tabular}

The fact that both sets of GA scores resulted in the same schools being assigned to the two climate groups further supports the claim that this study demonstrates 
a close association with the model of leadership effectiveness proposed by Fiedler.

\section{Final Phase Data}

$\underline{\text { Review of Procedure }}$

The effectiveness of the 12 administrative teams comprising the final sample was assessed through the use of the High School Characteristics Index (HSCI). A random selection was made of three sections in each school of a required twelfth-grade course in which students were randomly assigned. The students enrolled in the selected sections completed the HSCI. Student responses to the HSCI were reported on HSCI scale scan sheets. The scan sheets completed by the students from the 12 schools sampled were sent to the Test Scoring and Evaluation Services Department of Syracuse University for scoring.

\section{High School Characteristics Index Data}

A1l student HSCI scale response sheets containing more than five missing responses or otherwise not properly completed were rejected during the scoring procedure. Table 7 shows the number of scales returned, number of usable scales, mean developmental press HSCI scores, and standard deviation of the mean scores by school. The HSCI scores are listed in descending order.

A total of 835 scales were returned, of which 739 were usable. The HSCI scores ranged from a high of 176.500 to 
a low of 134.305. Fern High School was associated with the highest HSCI score, and the lowest score was indicated by Redwood High. The mean of the total mean HSCI scores, listed in Table 7, was 160.898. Stern (1970) reported a mean of 183.52 and a standard deviation of 36.55 for the developmental press HSCI score (p. 255). These data resulted from a study involving 947 respondents within 12 high schools. The mean of 160.8985 that was reported for the data listed in Table 7 is within one standard deviation of the mean reported by stern.

Table 7

Developmental Press HSCI Data

\begin{tabular}{lcccc} 
School & $\begin{array}{c}\text { Number } \\
\text { of scales } \\
\text { returned }\end{array}$ & $\begin{array}{c}\text { ivmber } \\
\text { of usable } \\
\text { scales }\end{array}$ & $\begin{array}{c}\text { Mean } \\
\text { HSCI } \\
\text { score }\end{array}$ & $\begin{array}{c}\text { Standard } \\
\text { deviation }\end{array}$ \\
\hline Fern High & 62 & 54 & 176.500 & 28.684 \\
Westbrook High & 64 & 53 & 170.660 & 26.160 \\
Space High & 90 & 85 & 170.624 & 25.795 \\
HighlandHigh & 77 & 68 & 168.088 & 34.404 \\
Pioneer High & 77 & 71 & 167.183 & 28.669 \\
Sand High & 56 & 51 & 166.157 & 22.380 \\
Ocean High & 61 & 55 & 165.364 & 35.016 \\
Summer High & 63 & 54 & 161.611 & 22.891 \\
Palm High & 77 & 69 & 153.956 & 27.447 \\
Southern High & 60 & 54 & 149.685 & 29.168 \\
Coast IIigh & 76 & 66 & 145.439 & 37.733 \\
Redwood High & 72 & 59 & 134.305 & 24.759 \\
\hline
\end{tabular}

As stated previously, the developmental press factor of the HSCI was identified by Stern (1970) as a measure of the quality of the learning environment afforded students. The greater the HSCI score, the more effective the 
administrative team is in providing experiences that enhance the development of human capacities (Bishop, 1971; Garland \& O'Reilly, 1976; Stern, 1970).

\section{Statistical Analysis of Data}

During the statistical analysis phase of this study, the five previously stated null hypotheses were tested. The following discussion of the analysis of the data is organized in a manner consistent with these hypotheses.

\section{Null iypothesis 1}

According to this null hypothesis the HSCI scores in final sample high schools led by principals having high LPC scores would not differ from the lisCI scores associated with principals indicating low LPC scores $(\underline{p}<.05)$.

Table 8 shows the high and low LPC principals listed with their respective LPC and HSCI scores by school. Schools being led by principals indicating high and low LPC scores are grouped separately in Table 8. Within each of these LPC groups the schools are listed in descending order of LPC score.

The scores for the highest LPC schools ranged from 119 to 70. Whereas the scores for low LPC schools ranged from 68 to 38. Among the high LPC schools, the principal of Space High indicated the highest LPC score, and the principal of sand High indicated the lowest LPC score. Among the low LPC schools, the principal of coast High 
indicated the highest LPC score, and the principal of Highland High indicated the lowest LPC score.

Table 8

Principals' LPC Scores and Team HSCI Scores

School

Principal's

LPC score
Team

HSCI score

IIigh LPC schools

$\begin{array}{lrr}\text { Space High } & 119 & 170.624 \\ \text { Palm High } & 96 & 153.956 \\ \text { Redwood High } & 93 & 134.305 \\ \text { Southern IIigh } & 87 & 149.685 \\ \text { Pioneer High } & 82 & 167.183 \\ \text { Sand High } & 70 & 166.157\end{array}$

Low LPC schools

Coast High

Summer High

Ocean High

Fern High

Westbrook High

Highland High
68

61

55

50

50

38
145.439

161.611

165.367

176.500

170.660

168.088

The reader will recall from the definitions section of Chapter I that the LPC score is the operational description of the leadership style employed by the principal. The higher the LPC score, the more relationship motivated is a leader. Lower LPC scores indicate that a leader tends to be task motivated. As previously defined, LPC scores 
greater than or equal to 70 on Fiedler's LPC scale indicate that a leader is relationship motivated. Less than 70 scored on the LPC scale indicates that a leader is task motivated.

Among the high LPC schools, the team HSCI scores ranged from a high score of 170.627 to a low score of 134.305. The highest team HSCI score was reported for Space High, and the lowest team HSCI score was reported for Redwood High. The mean of the team HSCI scores among these schools was 156.985 .

Among the low LPC schools, the team HSCI scores ranged from a high score of 176.500 to a low score of 145.439. The highest team HSCI score was reported for Fern High, and the lowest team HSCI score was reported for Coast High. The mean of the team HSCI scores among these schools was 164.610 .

The Kruskal-Wallis one-way analysis of variance procedure was used to test for the significant differences associated with hypothesis 1 . The 12 team HSCI scores for the two groups of schools were rank ordered from lowest to highest. These ranks are shown in Table 9. The $\underline{H}$ resulting from the Kruskal-Wallis one-way analysis calculation indicated that there were no significant differences between the effectiveness of the high LPC and low LPC groups of schools (II $(1)=.923 ; \underline{\mathrm{p}}<.05)$. Null hypothesis 1 was accepted. 
Table 9

Rank Order of Team HSCI Scores Indicated by High LPC and Low LPC Schools

High LPC schools

Space High

Palm lligh

Redwood High

Southern High

Pioneer High

Sand High

Low LPC schools

Coast High

Summer High

Ocean High

Fern High

Westbrook High

Highland High

\section{Null Hypothesis 2}

Null hypothesis 2 stated that the IISCI scores associated with final sample administrative teams indicating high GA scores would not differ from the HSCI scores associated with final sample administrative teams indicating low GA scores $(\underline{p}<.05)$. 
Development press HSCI data relevant to this hypothesis have been listed in Table 10. The schools are listed according to descending order of mean HSCI scores within both the high GA schools and low GA schools groups.

Table 10

Developmental Press HSCI Data Indicated by High GA and Low GA Schools

Schools

Team HSCI scores

High GA schools

Fern High

Westbrook lligh

Highland High

Sand High

Palm High

Redwood High
176.500

170.660

168.088

166.157

153.956

134.305

Low GA schools

Space High

$\mathrm{Pioneer} \mathrm{High}$

Ocean High

Summer High

Southern High

Coast IIigh
170.624

167.183

165.364

161.611

149.685

145.439

The reader will recall from a previous discussion in

this chapter that high GA schools have administrative teams that perceive their groups' climates as being most cooperative according to the definition provided in chapter $I$. 
Low GA schools are likewise categorized according to the definitions in Chapter I. Administrative teams assigned to the low GA schools category perceive their groups' climates as being least cooperative.

Among the high GA schools, the team liSCI scores ranged from a high of 176.500 to a low of 134.305. The highest mean HSCI score was indicated for Fern High, and Redwood High was associated with the lowest score. The mean of the team HSCI scores among these schools was 161.611 .

Among the low GA schools, the school mean HSCI scores ranged from a high of 170.624 to a low of 145.439. The highest mean HSCI score was indicated for space High, and Coast IIigh was associated with the lowest score. The mean of the team HSCI scores among these schools was 159.984 . The Kruskal-Wallis analysis of variance procedure was used to test for the significant differences associated with hypothesis 2. The 12 team HSCI scores for the two groups of schools were rank ordered from lowest to highest. These ranks are shown in Table 11 .

The $\mathrm{H}$ resulting from the Kruskal-Wallis one-way analysis calculation indicated that there were no significant differences between the effectiveness of the high GA and low GA groups of schools (H (1) $=.641 ; \underline{p}<.05)$. NuIl hypothesis 2 was accepted. 
Table 11

Rank order of Team HSCI Scores Indicated by High GA and Low GA Schools

\begin{tabular}{lc}
\hline Schools & $\begin{array}{c}\text { Team HSCI score } \\
\text { rank order number }\end{array}$ \\
\hline High GA schools & 12 \\
Fern High & 11 \\
Westbrook High & 9 \\
Highland High & 7 \\
Sand High & 4 \\
Palm High & 1 \\
Redwood High & \\
& \\
Low GA schools & \\
Space High & 10 \\
Pioneer High & 8 \\
Ocean High & 6 \\
Summer High & 5 \\
Southern High & 3 \\
Coast High & 2 \\
\hline
\end{tabular}

\section{Nul1 Hypothesis 3}

Null hypothesis 3 stated that there is no correlation between the LPC score of principals and the mean GA score among the initial sample administrative teams $(\underline{p}<.05)$.

Table 12 shows the LPC scores of principals and the mean GA scores of the schools associated with each specific LPC score. The LPC and GA scores are listed by school and are arranged according to descending mean GA score. The mean GA scores ranged from a high of 79.333 to a low of 61.500. Fern High was associated with the highest mean 
GA score, and coast liigh was associated with the lowest GA score. The LPC scores ranged from a high of 119 to a low of 34. Space High is associated with the highest LPC score listed and a mean GA score of 70.222. Pine Ridge High is associated with the lowest LPC score listed and mean GA score of 74.333 .

Table 12

LPC Scores and Mean GA Scores Listed by School

\begin{tabular}{lrr}
\hline & LPC & Mean \\
School & & GA score \\
\hline Fern High & 50 & 79.333 \\
Highland High & 38 & 77.118 \\
Westbrook High & 50 & 76.889 \\
Sand High & 70 & 76.875 \\
RedwoodHigh & 93 & 75.900 \\
Palm High & 96 & 75.375 \\
High Banks High & 51 & 75.300 \\
Beach High & 87 & 74.399 \\
Pine Ridge High & 34 & 74.333 \\
Lakeside High & 65 & 72.273 \\
Champion High & 87 & 72.133 \\
Central High & 107 & 71.600 \\
Union High & 70 & 70.879 \\
Northern High & 47 & 70.706 \\
Pioneer High & 82 & 70.455 \\
Ocean High & 55 & 70.222 \\
Space High & 119 & 65.539 \\
Summer High & 61 & 63.999 \\
Southern High & 87 & 61.500 \\
Coast High & 68 & \\
\hline
\end{tabular}

The Spearman Rank Correlation Coefficient was determined for the data shown in Table 12 to test null hypothesis 3. The LPC scores and the mean GA scores for the selected schools were rank ordered. As Roscoe (1975) 
recommended when tie scores were encountered, the ranks were summed and divided equally among the tied scores. Hence, scores that have the same numerical value also have the same rank (p. 107). These ranks are shown in Table 13.

Table 13

Rank order of LPC Scores and Mean GA Scores Indicated by the Initially selected Schools

\begin{tabular}{lcc}
\hline & $\begin{array}{c}\text { LPC score } \\
\text { School }\end{array}$ & $\begin{array}{c}\text { Mean GA score } \\
\text { rank order number }\end{array}$ \\
\hline Fern High & 4.5 & 20 \\
Highland High & 2 & 19 \\
Westbrook High & 4.5 & 18 \\
Sand High & 11.5 & 17 \\
Redwood High & 17 & 16 \\
Palm High & 18 & 15 \\
High Banks High & 6 & 14 \\
Beach High & 15.5 & 13 \\
Pine Ridge High & 1 & 12 \\
Lakeside High & 9 & 11 \\
Champion High & 15.5 & 10 \\
Central High & 19 & 9 \\
Union High & 11.5 & 7 \\
Northern High & 3 & 6 \\
Pioneer High & 13 & 5 \\
Ocean High & 7 & 4 \\
Space High & 20 & 3 \\
Summer High & 8 & 2 \\
Southern High & 14 & 1 \\
Coast High & 10 & \\
\hline
\end{tabular}

The calculation of the Spearman Rank Correlation Coefficient for the data shown in Table 13 did not detect a significant relationship $(\underline{r}=-.325 ; \underline{p}<.05 ; \mathrm{n}=20)$. Null hypothesis 3 was accepted. 


\section{Null Hypothesis 4}

Null hypothesis 4 stated that there is no correlation between the LPC score of principals and the mean HSCI score among the final sample schools having administrative teams that indicated high GA scores.

Table 14 shows the LPC scores of principals and the mean HSCI scores within the high GA schools. The HSCI scores are listed in descending order in Table 14. The HSCI scores ranged from a high of 176.500 to a low of 134.305. The highest HSCI score was reported for Fern High, while the lowest HSCI score was reported for Redwood High. The LPC scores ranged from a high of 96 to a low of 38 . Palm High was associated with the highest LPC score, while the principal of Highland High reported the lowest LPC score listed in Table 14. The principals of two schools, Fern High and Westbrook High, indicated an LPC score of 50 .

Table 14

Principals' LPC Scores and Team HSCI Scores Within High GA Schools

\begin{tabular}{lcr}
\hline School & $\begin{array}{c}\text { Principal's } \\
\text { LPC score }\end{array}$ & $\begin{array}{c}\text { Team } \\
\text { HSCI score }\end{array}$ \\
\hline Fern High & 50 & 176.500 \\
Westbrook High & 50 & 170.660 \\
Highland High & 38 & 168.088 \\
Sand High & 70 & 166.157 \\
Palm High & 96 & 153.956 \\
Redwood High & 93 & 134.305 \\
\hline
\end{tabular}


Testing of null hypotinesis 4 was accomplished by calculating the Spearman Rank Correlation Coefficient for the IPC and HSCI scores shown for each school listed in Table 14. The IPC scores and the HSCI scores were rank ordered according to the procedures followed in testing hypothesis 3. These ranks are shown in Table 15.

Table 15

Rank order of LPC Scores and HSCI Scores Within High GA Schools

\begin{tabular}{lcc}
\hline School & $\begin{array}{c}\text { IPC score } \\
\text { rank order number }\end{array}$ & $\begin{array}{c}\text { HSCI score } \\
\text { rank order number }\end{array}$ \\
\hline Fern High & 2.5 & 6 \\
Westbrook High & 2.5 & 5 \\
Highland High & 1 & 4 \\
Sand High & 4 & 3 \\
Palm High & 6 & 2 \\
Redwood High & 5 & 1 \\
\hline
\end{tabular}

The calculation of the Spearman Rank Correlation coefficient for the data shown in Table 15 did not detect a significant relationship $(\underline{\underline{r}}=-.754 ; \underline{\underline{p}}<.05 ; \mathrm{n}=6)$. Null hypothesis 4 was accepted.

\section{Nul1 Hypothesis 5}

Null hypothesis 5 stated that there is no correlation between the IPC score of principals and the mean HSCI score among the final sample schools having administrative teams that indicated low GA scores $(\underline{\underline{p}<.05)}$.

Table 15 shows the LPC scores of principals and the mean HSCI scores within the low GA schcols. The HSCI scores 
are listed in descending order in Table 16. The HSCI scores ranged from a high of 170.623 to a low of 145.439 . The highest HSCI score was reported for Space High, while the lowest HSCI score was reported for coast High. The LPC scores ranged from a high of 119 to a low of 55. Space High was associated with the highest LPC score, while the principal of Ocean High reported the lowest LPC score listed in Table 16 .

Table 16

Principals' LPC Scores and Team HSCI Scores within Low GA Schools

\begin{tabular}{lcc}
\hline School & $\begin{array}{c}\text { Principal's } \\
\text { LPC score }\end{array}$ & $\begin{array}{c}\text { Team } \\
\text { IISCI score }\end{array}$ \\
\hline Space High & 119 & 170.624 \\
Pioneer High & 82 & 167.183 \\
Ocean High & 55 & 165.364 \\
Summer High & 61 & 161.611 \\
Southern High & 87 & 149.685 \\
Coast High & 68 & 145.439 \\
\hline
\end{tabular}

Testing of null hypothesis 5 was accomplished by calculating the Spearman Rank Correlation Coefficient for the LPC and IISCI scores shown for each school listed in Table 14. The LPC scores and the HSCI scores were rank ordered according to the procedures followed in testing hypotheses 3 and 4. These ranks are shown in Table 17.

The calculation of the Spearman Rank Correlation 
Coefficient for the data shown in Table 17 did not detect a significant relationship $(\underline{\underline{r}}=.314 ; \underline{\mathrm{p}}<.05 ; \mathrm{n}=6$ ). Null hypothesis 5 was accepted.

$$
\text { Table } 17
$$

Rank Order of LPC Scores and HSCI Scores Within Low GA Schools

\begin{tabular}{lll}
\hline \multirow{2}{*}{ School } & LPC score & HSCI score \\
rank order number & rank order number \\
\hline
\end{tabular}

Space High

Pioneer High

Ocean High

Summer High

Southern High

Coast High

$\begin{array}{ll}6 & 6 \\ 4 & 5 \\ 1 & 4 \\ 2 & 3 \\ 5 & 2 \\ 3 & 1\end{array}$

\section{Chapter Summary}

The major data for this study were presented in this chapter. A description was given of the two phases of data collection associated with the research design selected for this study.

The administrative teams of $20 \mathrm{high}$ schools were the source of the primary phase data. The LPC scale was administered to the principals of the 20 selected high schools. Members of the 20 participating administrative teams completed the GA scale. The LPC scores indicated by the principals and the mean scores indicated by administrative team members were listed in this chapter. A rank order was 
presented of the mean GA scores. The six highest mean GA schools and the six lowest mean GA schools were selected for the final sample of subjects for this study.

The effectiveness of the administrative teams comprising the final sample was measured by administering the HSCI to a random sample of senior students from each administrative team's school. The mean developmental press factor score of the HSCI measurement for each school was listed in this chapter.

The statistical analysis of the data presented in this chapter yielded the following findings:

1. No significant differences were detected between the effectiveness scores of the teams led by principals labeled high LPC leaders and the teams led by the principals labeled low LPC leaders.

2. No significant differences were detected between the effectiveness scores indicated by high GA teams and low GA teams.

3. No significant correlation was found between the LPC score of principals and the mean GA score among the 20 initially selected administrative teams.

4. No significant correlation was found between the LPC score of principals and the mean effectiveness score among administrative teams classified as high GA teams.

5. No significant correlation was found between the LPC score of principals and the mean effectiveness score among administrative teams classified as low GA teams. 
CHAPTER IV

DISCUSSION AND EXPLANATION OF FINDINGS

The data obtained from this study are fundamental to answering the research questions associated with the research problem. Also important is the relationship of the data to selected literature. This chapter includes a discussion of the data and of its relationship to the literature. This chapter is organized into sections that focus upon the relationships among the variables that are pertinent to the research questions associated with this study.

\section{Relationship Between Leadership Style and Team Effectiveness}

The relationship between the leadership style of principals and the effectiveness of high school administrative teams was the focus of research question 1 . The findings associated with this research question are discussed and related to selected literature in this section of Chapter IV.

Findings Associated with Question 1

Research question 1 was stated in chapter I in the following manner: Is there a relationship between the 
leadership style of principals and the effectiveness of high school administrative teams?

The Least Preferred Coworker (LPC) scale and the litigh School Characteristics Index (HSCI) were used to measure the leadership style of the principals and the effectiveness of the administrative teams respectively. As part of the process of answering this research question, principals' leadership styles were classified into relationship-motivated and task-motivated leader categories. Relationship-motivated principals scored 70 or higher on the LPC scale, and task-motivated principals scored less than 70 on the LPC scale. HSCI scores indicated the extent to which students were provided with a self-actualizing environment. The operational definitions of both leadership style and group effectiveness presented in Chapter I were utilized in formulating the following null hypothesis: The HSCI scores in high schools led by principals having high LPC scores will not differ from the HSCI scores associated with principals indicating low LPC scores $(\underline{p}<.05)$.

The data in Chapter III showed that, according to the Kruskal-ivalis one-way analysis of variance, there was not a significant difference between the effectiveness of adninistrative teams led by relationship-motivated principals $(\underline{p}<.05)$. Consequently, it can be stated that no significant relationship between the leadership style of 
principals and the effectiveness of high school administrative teams was found by this investigation.

Relationship of Question 1 Findings to Selected Li terature

Research question 1 focused upon the relationship between leadership style and group effectiveness. The following discussion emphasizes the relationship of the findings associated with question 1 to selected literature. The writer stated previously that no significant relationship was found between the leadership style of principals and the effectiveness of high school administrative teams.

Fiedler (1967) reported that empirical investigations focusing upon the relationship between leadership style and group effectiveness date back to the 1938 studies of Lewin and Iippitt ( $p .12)$. As reported in Chapter II these early studies were expanded into an extensive study of three leadership styles by Lippitt and White (Olmsted, 1959, pp. 38-42). The three leadership styles studied by Lippitt and white were autocratic, democratic, and laissez-faire. A large number of studies have been stimulated by this pioneer work of Lewin, Lippitt, and White. Stogdill (1974) reported that although numerous studies have focused upon democratic and autocratic leadership styles, significant Findings supporting one leadership style over arother are not consistentiy reported in the literature (p. 370). 
During the 1950s, studies conducted at ohio state University focused upon the behaviors exhibited by leaders demonstrating differing leadership styles. These studies contributed much knowledge to the field of leadership theory, but the findings associated with these studies were not consistent over differing leadership situations (House et a1., 1971; Ivancevich et a1., 1977).

The reader will note that the leadership situation was not a factor associated with research question 1 of this study. The lack of significant findings in the answering of question 1 is consistent with these reports in the literature of research focusing upon the relationship of various leadership style categories to group effectiveness. Studies relating the leadership style classifications developed by Fiedler and utilized in this study have been reported in the literature. Hopfe (1968) conducted a study among college department chairpersons in which the Least Preferred Coworker (LPC) score of leaders was compared with effectiveness ratings of the departments studied. The departments were not separated into most cooperative (high $\mathrm{GA}$ ) and least cooperative (low GA) groups by the investigator. Hopfe found that departmental performance was not significantly correlated with leaders' LPC scores $(\underline{r}=.048 ; \underline{p}<.05)$. This finding is consistent with the findings associated with question 1 . 
Fiedler (1967) reported that his early research was directed toward determining the leadership style that is most appropriate for fostering high effectiveness among groups (pp. 39-42). As his research continued, it became apparent that the relationship between leadership style and effectiveness depends upon factors within the leadership situation. A factor identified as a pertinent element to the leadership situation was the relationship between the group members and the leader. This factor was not included as an element in this research question, and the lack of a significant finding associated with question 1 is consistent with Fiedler's approach to leadership theory.

\section{Relationship Between Organizational Climate} and ream Effectiveness

The relationship between the organizational climate within high school administrative teams and the effectiveness of these groups was the focus of research question 2 . The findings associated with this research question are discussed and related to selected literature in this section of Chapter IV.

Findings Associated with Question 2

Following is research question 2 as stated in Chapter 1: Is there a relationship between the organizational climate of the administrative team and the effectiveness of the administrative team? 
The Group Atmosphere (GA) scale and the High School Characteristics Index (HSCI) were used to measure the organizational climate and the effectiveness of the administrative teams respectively.

During the process of answering this research question, the administrative teams were classified into most cooperative (high GA) and least cooperative (low GA) organizational climate groups according to the definitions stated in Chapter 1. The operational definitions of both organizational climate classifications and group effectiveness presented in Chapter I were utilized in formulating the following null hypothesis: The HSCI scores associated with administrative teams indicating high GA scores will not differ from HSCI scores associated with administrative teams indicating Iow GA scores $(\underline{p}<.05)$.

When this null hypothesis was tested with the KruskalWallis one-way analysis of variance as shown in chapter III, no significant difference was detected between the effectiveness of the most cooperative administrative teams and the least cooperative administrative teams ( $\underline{p}<.05)$. Therefore, it can be stated that there was not a significant relationship between the organizational climate of the administrative team and the effectiveness of the adninistrative teams associated with this study.

Relationship of Question 2 Findings to Selected Literature

Research question 2 focused upon the relationship 
between leadership style and group effectiveness. The following discussion emphasizes the relationship of the findings associated with question 2 to selected literature. The reader will recall that no significant relationship was found between the organizational climate within the selected administrative teams and the effectiveness of these groups.

This finding was consistent with research results reported by Garland and O'Reilly (1976). Garland and o'Reilly reported that the performance of good-groupatmosphere groups did not differ significantly from that of poor-group-atmosphere groups when the groups were led by the entire spectrum of leadership style principals.

A conclusion drawn by Hill (1972) further supports the findings of this study. Hill indicated that findings generally reported in the literature do not indicate that ccoperative organizational climate has "either positive or negative consequences for the recipients of the organization's action" (1972, p. 323).

It is found in the Iiterature that employee turnover and employee satisfaction are affected by organizational climate. Bayfield and crockett (1955) and csoka (1972) reporced that while labor turnover reduction and increased employee satisfaction can be enhanced by a cooperative organizational climate, a cooperative climate does not tend to increase group effectiveness. 
Fiedler and Chemers (1974) reported that there is little empirical evidence from field studies that one type of organizational climate is more likely to foster a different level of effectiveness than another type of climate (p. 110). This report by Fiedler and chemers is consistent with the findings associated with research question 2 reported for this study.

\section{Relationship Between Leadership Style and Organizational Climate}

The relationship between the leadership style of principals and the organizational climate found within high school administrative teams was the focus of research question 3. The findings associated with this research question are discussed and related to selected literature in this section of chapter IV.

\section{Findings Associated with Question 3}

The writer presented the following statement of research question 3 in chapter I: Is there a relationship between the leadership style of principals and the organizational climate of administrative teams?

The Least Preferred Coworker (IPC) scale and the Group Atmosphere (GA) scale were used to measure the leadership style of the principals and the organizational climate of the administrative teams respectively. 
The null hypothesis associated with this particular research question was as follows: There is no correlation between the LPC score of principals and the mean GA score among the 20 initially selected administrative teams $(\underline{p}<.05)$.

Testing of this null hypothesis was accomplished by calculating the Spearman Rank Correlation Coefficient for the pairs of scores associated with this hypothesis. This analysis did not detect a significant correlation between the variables associated with research question 3 ( $\underline{p}<.05)$. Hence, it was found that there was no significant relationship between the leadership style of principals and the organizational climate of the high school administrative teams who participated in this study.

Relationship of question 3 Findings to Selected Literature

Research question 3 focused upon the relationship between leadership style and organizational climate. The following discussion emphasizes the relationship of the findings associated with question 3 to selected literature. The reader will recall that no significant relationship was found between the leadership style of principals and the organizational climate within high school administrative teams.

Contrary to the findings of this study, Gibson, Ivancevich, and Donnelly (1973) reported that leadership 
styles are a major force in creating the climate of the organization (p. 318). Likert (1961) reported similar contradictory findings.

IMCGregor (1960) suggested that the leacier's style is not necessarily related to the climate of the relationship among group members. It was stated by McGregor that while the superior exerts more control than the subordinates over the nature of the organizational climate, personal attitudes and prejudices can affect the leader's influence over the situation ( $p$. 142). These comments made by McGregor support the plausibility of the findings of this study. It seems appropriate to review the leadership style construct utilized in this study. The relationship- and taskmotivated continuum developed by Fiedler (1967) describes the need structure of the leader. This need structure, measured by the LPC scale, affects a leader's performance in a rather complex manner. A leader's exhibited leadership style may vary according to the conditions among which the leader is operating. In instances where relationshipmotivated leaders have their relationship needs met, they will concern themselves "with such status-enhancing activities as ordering people around, assigning tasks and assuming responsibility" (Fiedler \& Chemers, 1974, p. 78). According to Fiedler (1972) the observable style or behavior of the leader is likely to change in response to the leader's need-satisfaction balance. A high or low LPC 
leader does not exhibit relationship-motivated or taskmotivated leadership behavior in all leader-group member encounters. Therefore, the opportunity for the leadership style to interact in a consistent manner with organizational climate is minimal. Not finding a significant relationship between the leadership style of principals and the organizational climate of the administrative teams is consistent with Fiedler's theoretical view of the relationship studied through this research question.

Interrelationships Among Leadership Style, organizational Climate, and Team Effectiveness

The interrelationships among leadership style, organizational climate, and team effectiveness were the focus of research questions 4 and 5 . Research questions 4 and 5 both include all three factors essential for a study based upon the theoretical model of leadership effectiveness proposed by Fiedler (1967). The three factors included in these two research questions were the leadership style employed by the high school principal, the principal's leadership situation, and the effectiveness of the group being led.

Inasmuch as the findings of the research questions being discussed are closely related to the contingency model of leadership effectiveness proposed by Fiedler, a review of this model is presented for the reader. This review of the contingency model is followed by a discussion 
of the findings of research questions 4 and 5 . The findings associated with both questions are related to selected literature in this section of chapter IV.

Review of Fiedler's Contingency Model

Fiedler (1967) advanced the concept that the effectiveness of a group is contingent upon the relationship between the style of leadership employed by the leader and the nature of the leadership situation (p. 15).

The leadership situation was described by Fiedler as being comprised of three elements: (a) task structure, (b) the leader's position power, and (c) group atmosphere. Fiedler further categorized the leadership situation into eight categories that he labeled octant 1 through octant 8. This conceptualization of the leadership situation is shown in Figure 1. The three major elements used to describe the leadership situation that are shown in Figure 1 are categorized as follows: (a) the task structure is categorized as either structured or unstructured; (b) the leader's position power is categorized as either strong or weak; and (c) the group atmosphere is categorized as either good or poor.

The description of the high school leadership situation according to the contingency model was presented in Chapter II. This description identified the leadership situation in a large high school as one in which the position power of the principal is high and the task of the 
administrative team is relatively unstructured. Referring to Table 18, one can identify a study extending the contingency model within a high school setting into octants 3 and 7 of the model.

Table 18

$$
\begin{gathered}
\text { Categorization of the Leadership Situation } \\
\text { According to Octants }
\end{gathered}
$$

\begin{tabular}{llll}
\hline $\begin{array}{c}\text { Octant } \\
\text { number }\end{array}$ & $\begin{array}{c}\text { Task } \\
\text { structure }\end{array}$ & $\begin{array}{c}\text { Leader } \\
\text { position } \\
\text { power }\end{array}$ & $\begin{array}{c}\text { Group } \\
\text { atmosphere }\end{array}$ \\
\hline 1 & structured & strong & good \\
2 & structured & weak & good \\
3 & unstructured & strong & good \\
4 & weak & good \\
5 & structured & strong & poor \\
6 & unstructured & strong & poor \\
7 & unstructured & weak & poor \\
8 & & & \\
\hline
\end{tabular}

Fincings Associated with Question 4

The following statement of research qeustion 4 was presented in Chapter I: Is there a relationship between the leadership style of principals and the effectiveness of high school administrative teams having a most cooperative organizational climate?

The Ieast Preferred Coworker (IPC) scale and the High School Characteristics Index (HSCI) were used to measure the leadership style of the principals and the effectiveness of the administrative teams respectively. The reader will recall that only administrative teams indicating a 
most cooperative organizational climate, according to the definitions presented in Chapter $I$, were included in the study of this research question.

The null hypothesis for testing this research question concerned with the leadership style-group effectiveness relationship within a most cooperative climate was stated as follows: There is no correlation between the LPC score of principals and the mean HSCI score among the selected schools having administrative teams that indicated high GA scores $(\underline{p}<.05)$.

The Spearman Rank Correlation Coefficient calculated in the process of testing this hypothesis did not detect a significant correlation $(\underline{r}=-.754 ; \underline{p}<.05 ; \mathrm{n}=6)$. Therefore, a significant relationship was not found between the leadership style of principals and the effectiveness of high school administrative teams having a most cooperative group climate.

Relationship of question 4 Findings to selected Literature

Research question 4 focused upon the relationship between leadership style and group effectiveness within a most cooperative organizational climate setting. The following discussion emphasizes the relationship of the findings associated with question 4 to selected Iiterature. As stated previously, no significant relationship was found between the leadership style of principals and the 
effectiveness of high school administrative teams having a most cooperative group climate.

The leadership situation associated with the problem of this study was previously described in this chapter as fitting into octants 3 and 7 of the contingency model developed by Fiedler. This particular research question focused upon a leadership situation in which the leader's position power is high, task is unstructured, and leadermember relations are most cooperative. The definition of a most cooperative group climate provided in Chapter I is consistent with a good group atmosphere as described by Fiedler (1967). As indicated in Figure 1, findings associated with research question' 4 are derived from a leadership situation consistent with octant 3 of the contingency model. The principals operating in the most cooperative organizational climate are most appropriately assigned to octant 3 of the contingency model (Fiedler \& Chemers, 1974; Garland \& O'Reilly, 1976).

After conducting 12 studies of groups operating within the leadership situation described by octant 3 of the contingency model, Fiedler (1967) reported a median correlation of -.33 between the leader LPC and group effectiveness. Fiedler is suggesting that a leader with a low LPC score or a task-motivated leader is more likely to be effective than a relationship-motivated leader in octant 3 . 
The correlation coefficient that was determined when the null hypothesis associated with this research question was tested was not significant $(\underline{r}=-.754 ; \underline{p}<.05 ; \mathrm{n}=6)$. Although this null hypothesis was not rejected, several comments concerning this finding should be made. The sign of the correlation coefficient found in answering this research question is in the direction predicted by the contingency model and shown in Table 1 . Fiedler (1967) suggested that a negative correlation is to be expected when research questions are focused upon octant 3 of the contingency model. Negative correlations between LPC scores indicate that task-motivated principals are likely to be associated with the most effective administrative teams. While such a generalization cannot be made for the insignificant correlation found for question 5 of this study, Fiedler and Chemers (1974) placed importance on such findings. Fiedler and chemers list the nonsignificant findings of studies associated with the contingency model as important validations of the contingency model (p. 82).

Hunt (1967) reported a correlation coefficient of $\underline{r}=-.80$ for a study associated with octant 3 of the contingency model. This finding by llunt was not statistically significant. Commenting on Hunt's finding, Fiedler (1967) made the following statement:

Hunt's work supports the main hypothesis of the Contingency Model and thus provides further 
validation of the model for interacting groups in real-life business and industrial organizations. (p. 176)

The writer emphasizes the lack of statistical significance associated with this finding. It does seem appropriate to add the findings determined through answering this research question to the body of knowledge associated with Fielder's theoretical model of leadership effectiveness.

Findings Associated with Question 5

The following statement of research question 5 was presented in chapter 1: Is there a relationship between the leadership style of principals and the effectiveness of high school administrative teams having a least cooperative group climate?

The Least Preferred Coworker (LPC) scale and the High School Characteristics Index (HSCI) were used to measure the leadership style of the principals and the effectiveness of the administrative teams respectively. The reader will recall that only administrative teams indicating a least cooperative organizational climate, according to the definitions presented in Chapter 1 , were included in the study of this research question.

The null hypothesis for testing this research question concerned with the leadership style-group effectiveness relationship within a least cooperative clinate was stated as follows: There is no correlation between the LPC 
score of principals and the mean HSCI score among the selected schools having administrative teams that indicated low GA scores $(\underline{p}<.05)$.

Testing of this null hypothesis by calculating the Spearman Rank Correlation Coefficient for the pairs of scores associated with this hypothesis did not detect a significant correlation between these variables $(\underline{p}<.05)$. Therefore, it was found that there is no significant relationship between these variables $(\underline{\underline{p}}<.05)$. Hence the writer states that there is no significant relationship between the leadership style of principals and the effectiveness of high school administrative teams having a least cooperative group climate.

\section{Relationship of Question 5 Findings} to selected Literature

Research question 5 focused upon the relationship between leadership style and team effectiveness within a least cooperative organizational climate setting. The following discussion will emphasize the relationship of the findings associated with question 5 to selected literature. As stated previously, no significant relationship was found between the leadership style of principals and the effectiveness of high school administrative teams having a least cooperative group climate.

This particular research question focused upon a leadership situation in which the leader's position power 
is high, task is unstructured, and leader-member relations are least cooperative. The reader is reminded that the definition of a least cooperative group climate provided in Chapter I is consistent with a poor group atmosphere as described by Fiedler (1967). As indicated in Figure 1, findings associated with research question 5 are derived from a leadership situation consistent with octant 7 of the contingency model. The principals operating in the least cooperative organizational climate are most appropriately assigned to octant 7 of the contingency model (Fiedler \& Chemers, 1974; Garland \& O'Reilly, 1976).

The correlation coefficient that was determined when the null hypothesis associated with this research question was tested was not significant $(\underline{r}=.314, \underline{p}<.05 ; \mathrm{n}=6)$. Although the null hypothesis cannot be rejected in this instance, several aspects of this finding merit comment.

The sign of the correlation coefficient found in answering this research question is in the direction predicted by the contingency model and shown in Table 1 . Fiedler (1967) suggested that a positive correlation is to be expected when research questions are focused upon octant 7 of the contingency model. Positive correlations between LPC scores indicate that relationship-motivated principals are likely to be associated with the most effective administrative teams. While such a generalization cannot be made for the insignificant correlation found 
for question 5 of this study, Fiedler (1973) placed importance on such findings. Commenting further on this issue Fiedler cites the small, insignificant correlations upon which the theoretical construct of octant 7 is based. The median correlation determined for the 12 original octant 7 studies was .05 . In reference to this original median correlation coefficient Fiedler (1973) commented, "Why should we not expect similarly nonsignificant correlations in validation studies?" (p. 359).

Hunt (1967) conducted a series of field studies that resulted in four correlations between leaders' LPC scores and group effectiveness. None of these correlations were statistically significant, $\underline{p}<.05$.

In reference to Hunt's investigations, Hill (1969) made the following comment:
Although none of the correlations. . . reached an acceptable level of significance, they do generally fit into the results predicted by Fiedler. . . and thus a partial confirmation is warranted. (p. 44)

Fiedler and Chemers (1974) stated that the median correlation for field studies conducted during validation studies associated with octant 7 is.30. The correlation coefficient, although not statistically significant, found in the process of answering this research question is .314. Since a positive correlation is in the direction predicted by the contingency model, Hill (1969) states that "a partial confirmation is warranted" (p. 44). 
Gordon, Loveland, and Cureton (1952) reported that the direction of correlations not statistically significant should be considered important. Gordon et al. further stated that as the findings from several studies are accumulated, it is appropriate to base a new test of significance on the combined data from all studies (p. 314). Fiedler (1973) reported that he utilized the statistical techniques recommended by Gordon et al. in analyzing the data upon which the contingency model of leadership effectiveness was based.

The lack of statistical significance associated with this finding is emphasized by the writer. It also seens important to add the findings determined through answering this research question to the body of knowledge associated with Fiedler's theoretical model of leadership effectiveness.

\section{Chapter Summary}

The data for this study were discussed in this chapter. The presentation was organized according to the following four sets of relationships that are relevant to the research problem: (a) relationship between leadership style and group effectiveness, (b) relationship between organizational climate and group effectiveness, (c) relationship between leadership style and organizational climate, and 
(d) interrelationships among leadership style, organizational climate, and group effectiveness.

The data relevant to the five research questions associated with the problem of this study were discussed in conjunction with the appropriate sets of relationships previously identiried. The statistical significance of the findings relevant to each research question was discussed. The findings associated with none of the five research questions were statistically significant.

The relationship of the data to selected literature was discussed within each major section of this chapter. The findings associated with each research question were discussed in relationship to relevant literature. Only the literature having direct bearing on the findings of this study was included. This chapter contains references to the applicability of the findings of this study to the theoretical model of leadership effectiveness presented by Fiedler in the literature. An argument was presented for accepting as important the findings that are not statisticaliy significant. 
CHAPTER V

SUMMARY, CONCLUSIONS, AND IMPLICATIONS

This chapter is presented in three major sections. The first section consists of a summary of this study. The conclusions based upon the findings of this study are presented next. The conclusions are followed by a discussion of implications for educational administrators that are pertinent to the study.

\section{Summary}

This study focused upon the interrelationships among leadership style, organizational climate, and group effectiveness among selected high school administrative teams. During the course of this investigation, the following questions were investigated:

1. Is there a relationship between the leadership style of principals and the effectiveness of high school administrative teams?

2. Is there a relationship between the organizational climate of the administrative team and the effectiveness of the administrative team?

3. Is there a relationship between the leadership style of principals and the organizational climate of the administrative teams? 
4. Is there a relationship between the leadership style of principals and the effectiveness of high school administrative teams having a most cooperative group climate?

5. Is there a relationship between the leadership style of principals and the effectiveness of high school administrative teams having a least cooperative group climate?

To provide the data associated with the research questions, the study focused first on 20 selected high school administrative teams. The 20 principals were mailed the Least preferred Coworker (LPC) scale, which they completed and returned to the researcher. The principal and all other members of the administrative teams of the 20 selected schools were mailed the Group Atmosphere (GA) scale, which they completed and returned to the researcher. The IPC scales completed by the principals were scored for later use. The GA scales were scored, and mean GA scores for each of the 20 administrative teams sampled were determined. The schools associated with the administrative teams were rank ordered according to the mean GA scores. A selection was made of the six administrative teams having the highest mean GA scores and the six administrative teams indicating the lowest GA scores. The schools associated with these 12 administrative teams were the focus of the final phase of the data collection for this study. High GA 
administrative teams were labeled as most cooperative groups, and low GA administrative teams were labeled as least cooperative groups.

A cluster sample of twelfth-grade students from the 12 schools selected for the final phase of data collection completed the High School Characteristics Index (HSCI). This index was utilized as a measure of the effectiveness of the administrative teams in providing an appropriate developmental environment for learning within the school. The HSCI scales were scored, and mean HSCI scores for each of the 12 schools selected for this phase of data collection were determined.

The data analyzed in the process of testing the null hypotheses associated with this study's research questions came from the following sources: (a) LPC scores indicated by principals, (b) mean GA scores indicated by administrative tearn members, and (c) mean IISCI scores determined from student ISCI scale responses.

The findings of this study are summarized into five statements. These statements are presented in an order consistent with the listing of the five research questions that were presented in the opening section of this chapter. The conclusions following this section are based on these findings:

1. The leadership style of the selected final sample principals was not significantly related statistically to 
the effectiveness of the high school administration team $(\underline{H}(1)=.923 ; \underline{p}<.05)$.

2. The organizational climate of the final sample administrative teams in this study was not significantly related statistically to the effectiveness of the high school administrative team $(\underline{H}(1)=.641 ; \underline{p}<.05)$.

3. The leadership style of the selected initial sample principals was not significantly related statistically to the organizational climate of the administrative team $(\underline{r}=$ $-.325, \underline{p}<.05 ; \mathrm{n}=20)$.

4. The leadership style of the final sample principals in this study was not significantly related statistically to the effectiveness of high school administrative teams having a most cooperative group climate $(\underline{r}=-.754 ; \underline{p}<.05 ; \mathrm{n}=6)$.

5. The leadership style of the final sample principals in this study was not significantly related statistically to the effectiveness of high school administrative teams having a least cooperative group climate $(\underline{r}=.314 ; \underline{p}<.05 ; \mathrm{n}=6)$.

\section{Conclusions}

The primary emphasis of this research was to examine the interrelationships among leadership style, organizational climate, and administrative team effectiveness among selected high school administrative teams. A secondary emplasis of the research was to examine the relevance of the contingency model of leadership effectiveness for selected high schools. 
The following five conclusions are based upon the findings of no statistically significant relationships during the process of answering the research questions associated with this study. These conclusions include references to the contingency model of leadership effectiveness when pertinent to the discussion:

1. There is no relationship between the leadership style of principals and the effectiveness of high school administrative teams.

2. There is no relationship between the organizational climate of the administrative team and the effectiveness of the administrative team.

3. There is no relationship between the leadership style of principals and the organizational climate of the administrative teams.

4. There is no relationship between the leadership style of principals and the effectiveness of administrative teams having a most cooperative group climate. Statements found in the literature suggested that the negative direction of the correlation that was associated with this relationship is important (Fieảler, 1973; Hill, 1969; liunt, 1967). Therefore, the writer concludes that this statistically insignificant relationship does provide information consistent with the contingency model of leadership effectiveness developed by Fiedler. 
5. There is no relationship between the leadership style of principals and the effectiveness of administrative teams having a least cooperative group climate. Statements found in the Iiterature suggested that the positive direction of the correlation that was associated with this relationship is important (Fiedler, 1973; Gordon, Loveland, \& Cureton, 1952; Hill, 1969). Therefore, the writer concludes that this statistically insignificant relationship does provide information consistent with the contingency model of leadership effectiveness developed by Fiedler.

\section{Implications for Educational Administrators}

This study of the interrelationships among leadership style, organizational climate, and group effectiveness among selected high school administrative teams suggested several implications for educational administrators. Certainly every high school principal aspires to be successful in providing leadership that will enhance the quality of the learning environment experienced by students. School district superintendents and other district level administrators also want principals to be effective leaders. pursuant to the discussion that follows, the writer realized that much additional research needs to be completed. The study reported herein had the obvious Iimitation of a restricted sample. Nevertheless, based on the direction of the data and on the research completed elsewhere, the 
implications discussed herein are, at least, partially supported. The writer presents these implications in the interest of contributing to leadership theory in educational administration.

Implications for the High School principals

The principals of high schools having enrollments in excess of 1,500 students accomplishes the administrative tasks associated with managing the organization by providing leadership for an administrative team. This administrative team consists of administrative assistants, deans, business managers, secretaries, and clerical assistants. The leadership situation in large high schools has been described in chapter II as one in which the position power of the principal is high and the task of the administrative team is relatively unstructured. The theoretical model upon which this study was based has been previously discussed. This model describes a high school principal's leadership as belonging in either octant 3 or octant 7 of the contingency model. The data in this study and knowledge of the contingency model of leadership effectiveness can be combined to enhance the leadership capabilities of the high school principal. There are several actions the principal can take that will result in an advantageous use of this knowledge. Initially, the leadership style of the principal needs to be identified. Fiedler, Chemers, and Mahar (1976) provide guidance in completing and scoring 
the LPC score and assessing one's leadership style along the task-motivated-relationship-motivated continuum (pp. 6-24). Next, the principal should become cognizant of the leadership situation within which he is operating. According to the definitions, instrumentation, and procedures of this study, principals leading a most cooperative administrative team are operating in a leadership situation consistent with octant 3 of the contingency model. Those principals associated with least cooperative administrative teams are operating within a leadership situation consistent with octant 7 of the contingency model.

Significant findings were not determined for the principal's leadership situation consistent with octant 3 or octant 7 of the contingency model. Supporters of Fiedler's Contingency Model reported in the literature that statistically significant findings are not necessary for a study's results to be consistent with the theoretical model. The data gathered by this study meet the criteria described in the literature that indicates support for the general concept of the contingency model. Fiedler (1967) stated the following argument favoring the use of the contingency model as a tool to enhance leadership effectiveness:

If the leader is made aware of his strengths and weaknesses as well as possible remedies, he may not only be able to modify group situations to match them with his leadership style, he may also learn how to avoid group situations 
which are incompatible with his style and seek out those in which he is most likely to succeed. (p. 259)

According to Fiedler, Chemers, and Mahar (1976) high school principals operating in both octant 3 and octant 7 settings can modify their leadership situation by adjusting the leader-member relations component of the situation. They suggest that the principal can establish a more cooperative climate of goodwill and trust among team members. Fiedler, Chemers, and Mohar (1976) made the following suggestion to the leader:

You can become socially more accessible to them so that they get to know you as a person, and you can try to provide them with accurate information about the organization so that you can earn their trust and confidence. (p. 53)

Relations-motivated principals associated with a setting where good group relations are easily established, as in octant 3 , may be reluctant to alter these interpersonal relations to have a more effective group. Fiedler, Chemers, and Mahar (1976) made the following comment related to this problem:

However, leader-member relations can become too close for effective task performance. Group nembers may complain about favoritism, or you may find that you cannot properly discipline a subordinate because he or she is your friend. It may then be necessary to increase the distance between your group and yourself. (p. 153)

Thus octant 3 and octant 7 situations can be interchanged by the high school principal's own initiative. 
This implication of the contingency model suggests that both task-motivated and relationship-motivated principals can be highly effective in the two leadership situations focused upon by this study.

Implications for School DistrictLevel Administrators

This study presents data that have implications for district-level administrators who are engaged in the supervision of high school principals.

A factor that supervisors of high school principals view as important is the effectiveness of the principals. There is a tendency to respond to needs for improving the effectiveness of leaders by prescribing training experiences for the leaders. The findings in the literature are not supportive of training as a tool for improving leadership effectiveness. Campbell, Dunnette, Lawler, and Weick (1970) reported that the major portion of the literature on leadership training does not demonstrate that the behavior changes that do result from training "have any importance for the organization's goals" (p. 325). Odiorne (1964) also reported that leadership training is a questionable method for improving the effectiveness of leaders. The findings and conclusions of this study indicate that the training opportunities provided for leaders need to emphasize the factors relevant to the theoretical model upon which this study was based. While Fiedler (1971) 
stated general agreement with the conclusions of Campbell et al. (1970) concerning the effectiveness of leadership training, he also suggested that different conclusions concerning leadership training are reached when findings are related to the contingency model. When training is related to the contingency model, the objectives of training experiences relate more realistically to the goal of improving leadership effectiveness. For example, human relations training is likely to improve leader-member relations, and technical training would make the task appear more structured. Leadership training geared to the constructs encompassed by Fiedler's model of leadership effectiveness has been found to be effective (Csoka, 1971; Fiedler, 1971).

The findings of this study and the theoretical basis of this study indicate that it is appropriate for supervisors of high school principals to provide training opportunities for leaders. One focus of these training experiences should be upon the various elements that comprise the leadership situation. Encouragement and appropriate resources should be provided for principals to assess their leadership style and situational circumstances. Fiedler, Chemers, and Mahar (1976) provided a guide that is suitable for high school principals to use in gaining this leadership knowledge. Thus, high school 
principals can manage their own leadership situation and enhance leadership effectiveness.

General Implications

The implications of this study for high school principals and the supervisors of high school principals have been discussed in this section. The writer suggests that further studies, similar in design to this investigation, be done. The writer suggests that a much larger sample be used in any future studies. The findings of this study do add significantly to the body of knowledge associated with leadership effectiveness. This knowledge can be appropriately related to the information provided by Fiedler's model of leadership effectiveness. The findings of this study add to an already powerful theory of leadership effectiveness. 
APPENDIX A

LETTER TO PRINCIPALS

2556 Middleton Avenue

Winter Park, Florida 32792

october 9,1978

Dear Principal:

In conjunction with my graduate studies at the University of Florida, I am gathering data concerning the interrelationships among leadership style, organizational climate, and high school administrative team effectiveness. This letter is a follow-up communication to our telephone conversation held during the week of october 2, 1978 .

The instruments that have been selected for use in this phase of the study are entitled the Least Preferred Coworker (LPC) and the Group Atmosphere (GA). Both of these scales can be completed by the respondents in less than three minutes. The LPC scale is to be completed by the principal only. The GA scale is to be completed by the principal, assistant principals, administrative assistants, and other school administrative personnel.

In order for the data gathered during this study to be meaningful, it is important for all of the selected administrative teams to participate in this phase of the study. During the later phase of this study a cluster sample of students, from $60 \%$ of the participating schools, will be requested to complete the $\mathrm{High}$ School Characteristics Index (HSCI). The HSCI can be administered in a single 50-minute class period.

No names of persons or schools will ever be published in reference to data gathered during this study. Please return the response froms to me as soon as possible. Stamped, addressed envelopes are being provided for the return mailing of the forms. Without your cooperation this effort cannot be a success. Your help is needed and will be greatly appreciated. Please contact me if you desire any additional information concerning this study.

Sincerely,

Wilfred F. Stili

Enclosures 
APPENDIX B

\section{HIGH SCHOOL CHARACTERISTICS INDEX}

ADMINISTRATION INFORMATION

The High School Characteristics Index (HSCI) is an instrument designed to measure elements of the climate of a high school. Three class sections of twelfth-grade students in several schools have been selected to complete the HSCI. A 50-minute class period is sufficient time for administering this instrument. Each high school participating in this program is being supplied with 50 copies of the index booklets and 120 answer sheets. As each of the three class sections is administered the instrument, the initial activity should be the distribution of the answer sheets. Although these particular answer sheets are printed on both sides of the sheet, only one side is to be used by students during this activity.

Students need to fill in the date of index administration, name of school, and their name in the appropriate spaces provided on the answer sheet. Other general information spaces may be left blank.

The index booklets should then be distributed, and the directions on the cover of the booklet should be reviewed with the students. It is important to remind students to read and respond to the questionnaire items as quickly as possible. Lengthy periods of thoughtful consideration of 
each item are not necessary for this instrument to be effective.

After a class section has been administered the HSCI, the test booklets and the completed and unused answer sheets are to be returned to the school-level study coordinator.

No names of students, teachers, administrators, or schools will ever be published in conjunction with the reporting of the results of this study. Any questions concerning the administration of this instrument should be directed to Wilfred Sti11, 2556 Middleton Avenue, Winter Park, Florida 32792 . 


\section{REFERENCES}

Anderson, L. W., \& Van Dyke, L. A. Secondary school administration. Boston: Houghton Mifflin, 1963.

Ashour, A. S. The contingency model of leadership effectiveness: An evaluation. Organizational Behavior and Human Performance, 1973, 9, $339-355$.

Bass, B. M. Leadership, psychology, and organizational behavior. New York: Harper, 1960 .

Bayfield, A. H., \& Crockett, W. H. Employee attitudes and employee performance. Psychological Bulletin, 1955, $\underline{52}, 396-429$.

Bell, N. H. Leader effectiveness within the North Carolina department of community colleges: An application and extension of Fiedler's contingency model to coacting groups (Doctoral dissertation, North Carolina state University at Raleigh, 1970). Dissertation Abstracts International, 1971, 31, 50574. (University Microfilms No. 71-10,263)

Bernard, J. Political leadership among North American Indians. American Journal of Sociology, 1928, 34, $296-315$.

Bird, C. Social psychology. New York: Appleton-Century, 1940 .

Bishop, L. K. Individualizing educational systems.

New York: Harper and Row, 1971.

Bogardus, E. S. Leaders and leadership. New York: Appleton-Century, 1934 .

Burns, T., \& Stalker, G. M. The management of innovation. London: Travistock Publications, 1961.

Campbell, J. P., Dunnette, M. D., Lawler, E. E., III, and Weick, K. E., Jr. Managerial behavior, performance, and effectiveness. New York: McGraw-liill Book Co., Inc. 1970 . 
Campbel1, R. F., Bridges, E. M. , \& Nystrand, O. Introduction to educational administration ( 5 th ed.) Boston: AlIyn and Bacon, 1977.

Chemers, M. M., \& Rice, R. W. A theoretical and empirical examination cf Fiedler's Contingency Model of leadership effectiveness. In J. G. Hunt \& L. L. Larson (Eds.), Contingency approaches to leadership. Carbondale, Ill.: Southern IIlinois University Press, 1974 .

Chemers, M. M. \& \& Skrzypek, G. T. An experimental test of the Contingency Model of leadership effectiveness. Journal of Personality and Social Psychology, 1972, $\underline{24}, 172-177$.

Chernow, F. B., \& Chernow, C. School administrator's guide to managing people. New York: Parker, 1976.

Corbally, J. E., Jr., Jensen, T. J., \& Staub, W. F. Educational administration: The secondary school. Boston: Allyn and Bacon, 1961.

Csoka, L. S. A Validation of the contingency model approach to leadership experience and training (TR-72-32). Seattle, Wash.: Organization Research Group, University of washington, February, 1972. (NTIS No. Ad-754-439)

Cunning, L. I., \& Gephart, W. J. Leadership: The science and the art today. Itasca, III.: Peacock, I973.

Curriculum Information center. CIC's school directory: School year 1978-79. Denver: Curriculum Information Center, 1978 .

Etzioni, A. Modern organizations. Englewood Cliffs, N.J.: Frentice-Hall, 1964 .

Evenson, W. L. Leader behavior of high school principals. National Association of Secondary School principals Bulletin, 1959, 43, 96-101.

Fiedler, F. E. The effect of leadership and cultural heterogeneity on group performance: A test of the contingency model. Journal of Experimental Social Psychology, $1966, \underline{2}, 237-264$.

Fiedier, F. E. A theory of leadership effectiveness.

iNew York: McGraw-Hill, 1967.

Fiedler, F. E. Style of circumstances: The leaders enigma. Psychology Today, 1969, $\underline{2}(10), 38-45$. 
Fiedler, F. E. Validation and extension of the contingency model of leadership effectiveness: $A$ review of empirical findings. Psychological Bulletin, 1971, 76, 128148.

Fiedler, F. E. Personality, motivational systems, and behavior of high and low LPC persons. Human Relations, $1972,25,391-412$.

Fiedler, F. E. The contingency model: A reply to Ashour. Organizational Behavior and Human Performance, 1973, $9,356-368$.

Fiedler, F. E., \& Chemers, M. M. Leadership and effective management. Glenview Ill.: Scott, Foresman, 1974.

Fiedler, F. E., Chemers, M. M. \& Mahar, L. Improving leadership effectiveness: The leader match concept. New York: John Wiley \& Sons, 1976.

Fleming, E. G. A factor analysis of the personality of high school leaders. Journal of Applied Psychology, $1935, \underline{19}, 596-605$.

Garland, P., \& O'Reilly, R. R. The effect of leader-member interaction on organizational effectiveness. Educational Administration Quarterly, $1976, \underline{12}(2), \overline{9-30}$.

Gibson, J. L., Ivancevich, J. M. , \& Donnelly, J. H. , Jr. Organizations: Structure, processes, behavior.

Gordon, M. H., Loveland, E. H., \& Cureton, E. E. An extended table of chi-square for two degrees of freedom, for use in combining probabilities from independent samples. Psychometrika, 1952, 17, 311-316.

Gorton, R. A. School administration: Challenge and opportunity for leadership. Dubuque, Iowa: Wm. G. Brown, 1976 .

Graen, G., Alvares, K., Orris, J. B. , \& Martella, J. A. The contingency model of leadership effectiveness: Antecedent and evidential results. Psychological Bulletin, 1970, 74, 285-296.

Halpin, A. Theory and research in administration. New York: Macmilian, 1966.

Halpin, A. W., \& Croft, D. B. The organizational climate of schools. St. Louis: Washington University, 1962. 
Hare, A. P. Situational differences in leader behavior. Journal of Abnormal Social Psychology, 1957, 55, $132-135$.

Hellriegel, D., \& Slocum, J. W., Jr. Organizational behavior contingency views. New York: West Publishing Company, 1976 .

Hemphill, J. K. Situational factors in leadership. columbus, ohio: Ohio State University, 1949.

Hill, R. H. Organizations: Structure and process. Englewood Cliffs, N.J.: Prentice-Hall, 1972 .

Hill, $W$. The validation and extension of Fiedler's theory of leadership effectiveness. Academy of Management Journal, 1969, 12(3), 33-47.

Holland, B. The principal and his administrative team. National Association of Secondary School Principals Bulletin, 1968, 52(331), 56-65.

Hopfe, M. W. A case of leadership in a college using Fiedler's contingency model (Doctoral Dissertation, Ohio University, 1968). Dissertation Abstracts International, 1969, 30, 133A. (University Microfilms No. 69-11,575)

House, R. J., Filley, A. C., \& herr, S. Relation of leader consideration and initiating structure to $R$ and $D$ subordinates' satisfaction. Administrative Science Quarterly, 1971, 16(3), 19-30.

Hunt, J. G. Fiedler's leadership contingency model: An empirical test in three organizations. Organizational Behavior and Human Performance, 1967, 2, 290-308.

Hunt, J.G. Leadership-style effects at two managerial levels in a simulated organization. Administrative Science Quarterly, 1971, 16, 476-485.

Ivancevich, J. M., Szilagyi, A. D., Jr., \& Wallace, M. J., $\mathrm{Jr}$. Organizational behavior and performance. Santa Monica, California: Goodyear Publishing, 1977.

James, W. Great man, great thoughts and their environment. Atlantic Monthly, 1880, 46, 441-459.

Jenkins, $w$. 0 . A review of leadership studies with particular reference to military problems. Psychological Bulletin, 1947, 44, 55-79. 
Jennings, E. E. An anatomy of leadership: Princes, heroes, and supermen. New York: Harper and Brothers, 1960 .

Johnson, D. W., \& Johnson, F. P. Joining together: Group theory and group skills. Englewood Cliffs, N.J.: Prentice-Hall, 1975.

Landers, T. J., \& Myers, J. G. Essentials of school management. Philadelphia: W. B. Sanders, 1977.

Lewin, K. Field theory in social science. New York: Harper Brothers publishers, 1951.

Likert, R. New Patterns of management. New York: McGraw-Hill, 1961 .

Mellor, K. P. An investigation of Fiedler's contingency model of leadership effectiveness as it applies to elementary school principals in Rhode Island (Doctoral dissertation, the University of Connecticut, 1974). Dissertation Abstracts International, 1974, 35, 1923A. (University Microfilms No. 74-21, 799)

McGregor, D. The human side of enterprise. New York: MCGraw-Hill, $\overline{1960}$.

Odiorne, G. S. The need for an economic approach to training. Journal of the American Society of Training Directors, 1964, 18, 3-12.

Olmsted, M. S. The small group. New York: Random House, 1959.

Posthuma, A. B. Normative Data on The Least-Preferred Co-worker (LPC) and the Group Atmosphere Questionnaire (GA). Seattle: University of Washington, 1970 .

Roscoe, J. T. Fundamental research statistics for the behavioral sciences (2nd ed.). New York: Holt, Rinehart and Winston, 1975.

Schultz, W. Leaders of schools. La Jolla, California: University $\lambda$ ssociates, 1977 .

Sherif, M., \& Sherif, C.W. Groups in harmony and tension. New York: Harper, 1953.

Siegel, S. Nonparametric statistics for the behavioral sciences. New York: McGraw-Hill, 1956. 
Stern, G. G. People in context, measuring personenvironment congruence in education and industry. New York: John Wiley, 1970.

Stogdill, R. M. Personal factors associated with leadership: A survey of the literature. Journal of Psychology, 1948, 25, 35-71.

Stogdil1, R. M. Handbook of leadership. New York: Macmillan, $1 \overline{974 .}$

Wallis, W. A., \& Roberts, H. V. Statistics: A new approach. Brooklyn, N.Y.: Macmillan, 1965.

Wetzel, W. A. Characteristics of pupil leaders. School Review, 1932, 40, 532-534.

Yunker, G. W. A field test of Fiedler's contingency model of leadership and a proposed revised model (Doctoral dissertation, Southern Illinois Universicy at Carbondale, 1972). Dissertation Abstracts International, 1973, 34, 17878. (University Microfilms No. $73-23,720)$ 
BIOGRAPHICAL SKETCH

Wilfred Franklin Still was born January 15, 1942, at Pottstown, Pennsylvania. He was graduated from Owen J. Roberts High School, Pottstown, Pennsylvania, in 1959. In 1966 he received the degree of Bachelor of Science with a major in secondary education and chemistry from west Chester State College in West Chester, Pennsylvania. Mr. Still continued his education at Rollins College, Winter Park, Florida, and was awarded the degree of Master of Educational Administration and Supervision in 1970 . In 1976, he began doctoral studies at the University of Florida.

During the period from 1966 to 1972, Mr. Still taught chemistry and general science at Crystal River High School, Crystal River, Florida, and at Maynard Evans High School in orlando, Florida. He is presently employed as assistant principal in the orange County, Florida, School system. 
I certify that I have read this study and that in my opinion it conforms to acceptable standards of scholarly presentation and is fully adequate, in scope and quality, as a dissertation for the degree of Doctor of Philosophy.

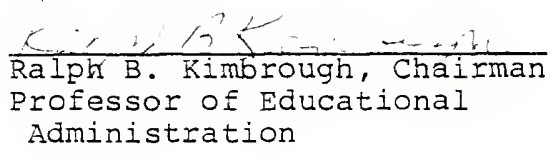

I certify that I have read this study and that in my opinion it conforms to acceptable standards of scholarly presentation and is fully adequate, in scope and quality, as a dissertation for the degree of Doctor of Philosophy.

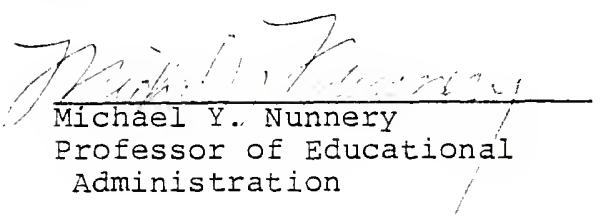

I certify that I have read this study and that in my opinion it conforms to acceptable standards of scholarly presentation and is fully adequate, in scope and quality, as a dissertation for the degree of Doctor of Philosophy.

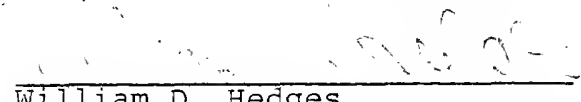

\author{
William D. Hedges \\ Professor of Curriculum and \\ Instruction
}

This dissertation was submitted to the Graduate Faculty of the Department of Educational Administration and Supervision in the College of Education and to the Graduate Council, and was accepted as partial fulfillment of the requirements for the degree of Doctor of Philosophy.

August, 1979

Dean, Graduate School 
UNIVERSITY OF FLORIDA

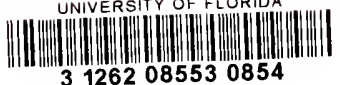

